\title{
WestVirginiaUniversity
}

THE RESEARCH REPOSITORY @ WVU

Graduate Theses, Dissertations, and Problem Reports

2020

\section{Impacts of Bike Sharing on Transit Ridership}

Moathe Salah Aljeri

moaljeri@mix.wvu.edu

Follow this and additional works at: https://researchrepository.wvu.edu/etd

Part of the Civil Engineering Commons, and the Transportation Engineering Commons

\section{Recommended Citation}

Aljeri, Moathe Salah, "Impacts of Bike Sharing on Transit Ridership" (2020). Graduate Theses, Dissertations, and Problem Reports. 7875.

https://researchrepository.wvu.edu/etd/7875

This Thesis is protected by copyright and/or related rights. It has been brought to you by the The Research Repository @ WVU with permission from the rights-holder(s). You are free to use this Thesis in any way that is permitted by the copyright and related rights legislation that applies to your use. For other uses you must obtain permission from the rights-holder(s) directly, unless additional rights are indicated by a Creative Commons license in the record and/ or on the work itself. This Thesis has been accepted for inclusion in WVU Graduate Theses, Dissertations, and Problem Reports collection by an authorized administrator of The Research Repository @ WVU. For more information, please contact researchrepository@mail.wvu.edu. 
Graduate Theses, Dissertations, and Problem Reports

2020

Impacts of Bike Sharing on Transit Ridership

Moathe Salah Aljeri

Follow this and additional works at: https://researchrepository.wvu.edu/etd

Part of the Civil Engineering Commons, and the Transportation Engineering Commons 


\title{
Impacts of Bike Sharing on Transit Ridership
}

Moathe Salah Aljeri

Thesis submitted

to the Benjamin M. Statler College of Engineering and Mineral Resources at West Virginia University

\author{
in partial fulfillment of the requirements for the degree of \\ Master of Science \\ in \\ Civil Engineering
}

\author{
Kakan C. Dey, Ph.D., Chair \\ David R. Martinelli, Ph.D. \\ V. Dimitra Pyrialakou, Ph.D. \\ Department of Civil and Environmental Engineering \\ Morgantown, West Virginia \\ 2020
}

Keywords: Citi Bike, Bike sharing, Subway, Ridership, Spatial regression Copyright 2020 Moathe Salah Aljeri 


\section{ABSTRACT \\ Impacts of Bike Sharing on Transit Ridership}

Moathe Salah Aljeri

Biking is an active, environmentally friendly, and sustainable transportation mode that facilitates short utilitarian and recreational trips. As such, cities around the world have been implementing bicycle sharing/renting programs at stations in a wide network so that a traveler can mount one close to their origins and drop it off at a station nearest to their destinations. In addition, bike sharing programs can solve the first-mile and last-mile connectivity problems of transit modes. Such programs also enable short trips that were previously impossible without using transit modes. This research investigated the relationship between New York City (NYC) subway ridership and the NYC bike sharing program known as Citi Bike. This study adopted the Spatial Lag Model (SLM) to explore the spatial dependencies between variables; moreover, the Ordinary Least Square (OLS) model was applied to compare the relative performance of SLM. The SLM coefficient estimates indicate that bike sharing trips around a subway station were positively associated. The number of bike sharing stations were negatively associated with subway ridership. This study's findings can be used to develop policies and initiatives that will help to better integrate bike sharing programs with transit services to increase the attractiveness of bike sharing programs and maximize subway ridership. 


\section{ACKNOWLEDGEMENTS}

To begin, I would like to thank Allah for making this opportunity possible for me and for guiding me throughout my personal and academic life - Alhamdulillah. He is the one who has the utmost favors and blessings over me. As the Prophet Muhammed, peace be a upon him, said: "He who does not thank the people is not thankful to Allah." I would also like to thank my parents for supporting me throughout all the difficult times to complete my bachelor's and master's degrees.

Moreover, I thank the committee chair Dr. Kakan Dey for his supervision of my master's thesis research, as well as Dr. David R. Martinelli and Dr. V. Dimitra Pyrialakou for serving in the committee and helping to guide my research. Finally, I would like to thank Md Amdad Hossen and Md Tanvir Ashraf for helping and supporting me throughout my graduate research. 


\section{Table of Contents}

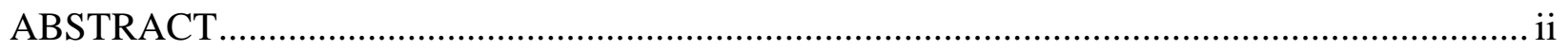

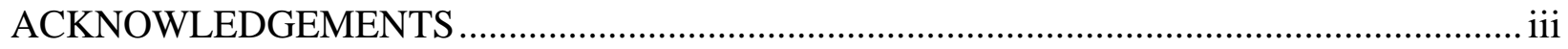

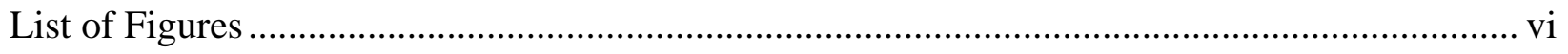

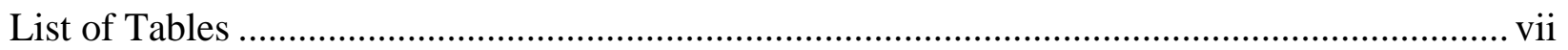

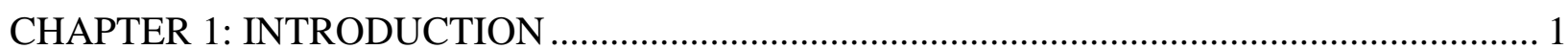

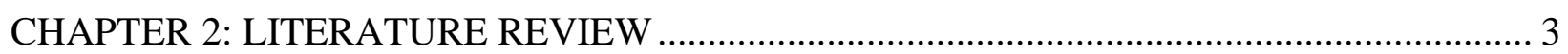

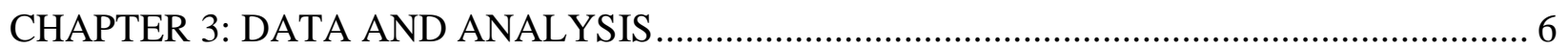

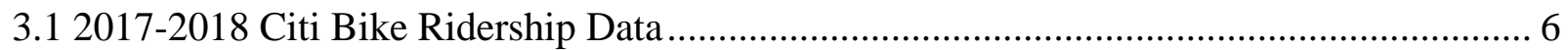

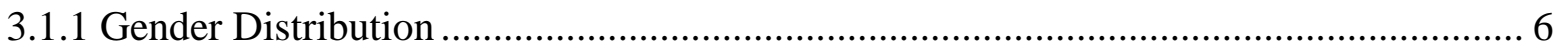

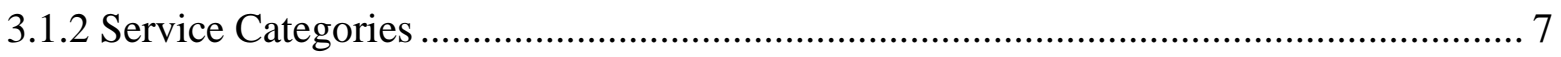

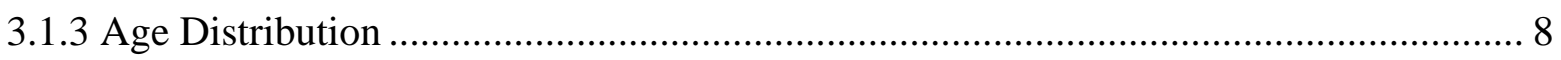

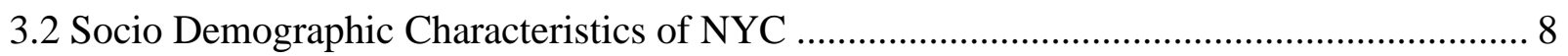

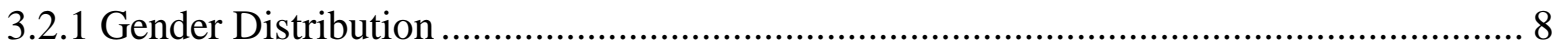

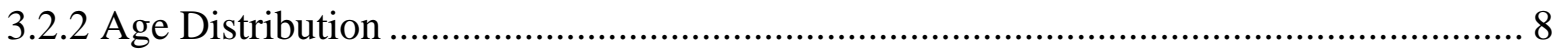

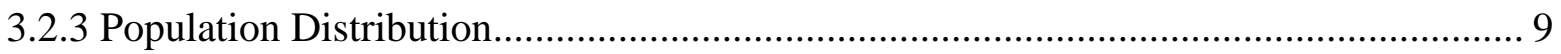

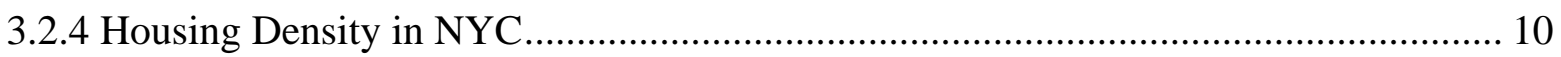

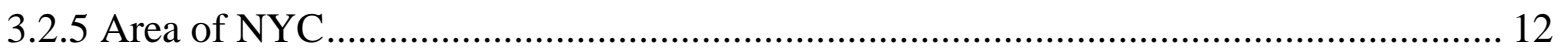

3.3 Modeling Variables used in this Research .............................................................. 13

3.3.1 Dependent Variable ................................................................................................. 14

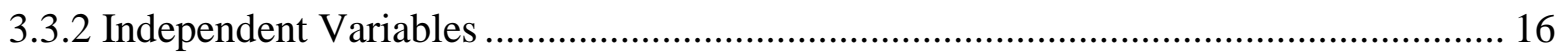

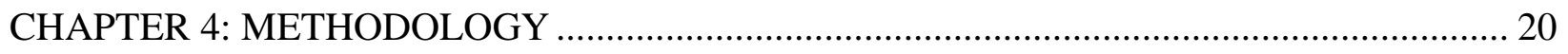

4.1 Measures of Spatial Autocorrelation.............................................................................. 20

4.2 Creating Weight Matrix …………………………….................................................. 21

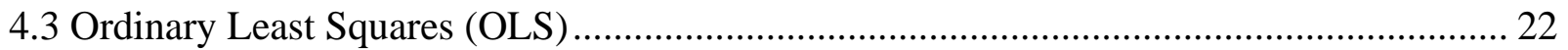

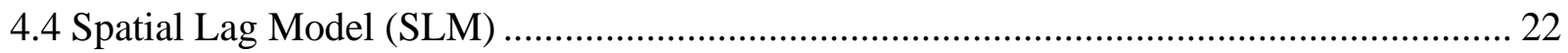

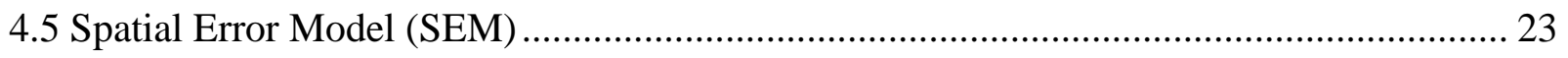

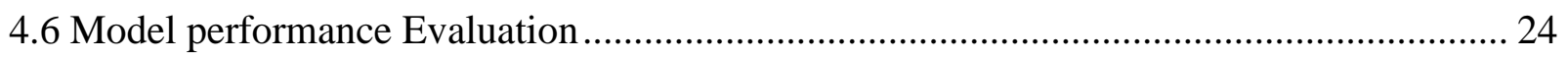

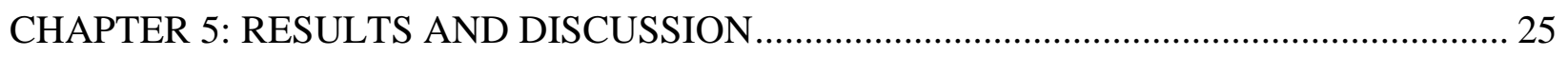

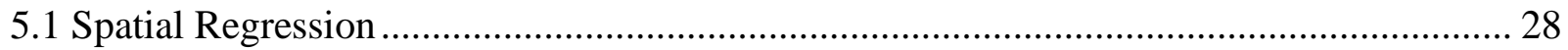

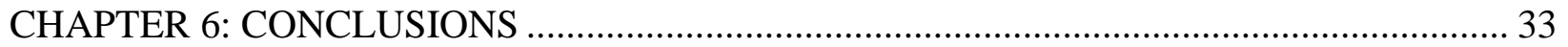

CHAPTER 7: RECOMMENDATIONS AND FUTURE RESEARCH DIRECTIONS ............... 34 
Impacts of Bike Sharing on Transit Ridership

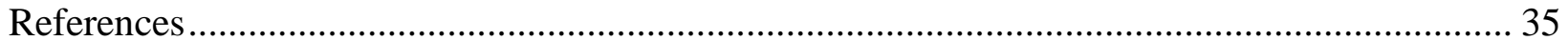




\section{List of Figures}

Figure 1: Type Of User Distribution Of Citi Bike Program From 2017-2018 (The Inner Circle Is Citi Bike Distribution In December 2017 And The Outer Circle Reflects Citi Bike Distribution In

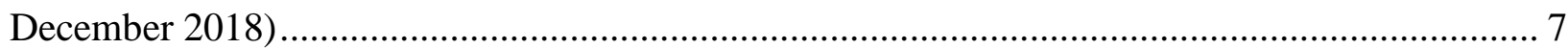

Figure 2: Age Distribution Of NYC Population Based On 2018 US Census ........................... 9

Figure 3: Population Density Of NYC In Square Mile Based On 2010 US Census In Thousands

Figure 4: Population Distribution Of NYC Population Based On 2010 US Census 10

Figure 5 : Housing Density Of NYC Per Square Mile Based On 2010 US Census In Thousands

Figure 6 : Housing Units In NYC Population Based On 2010 US Census ............................... 12

Figure 7: Area In Square Miles Of NYC Population Based On 2010 US Census .................... 12

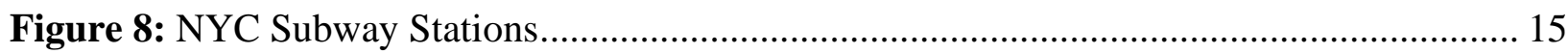

Figure 9: Subway Station With 1/4 Mile Radius And The Citi Bike Station In Accordance To

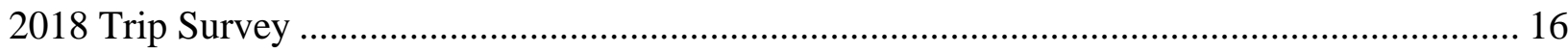

Figure 10: Citi Bike Stations In NYC According To The 2018 Trip Survey ........................... 17 


\section{List of Tables}

Table 1: Comparison Analysis Between December 2017 Trip Survey And December 2018 Trip

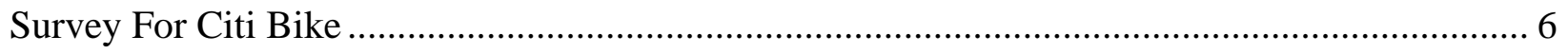

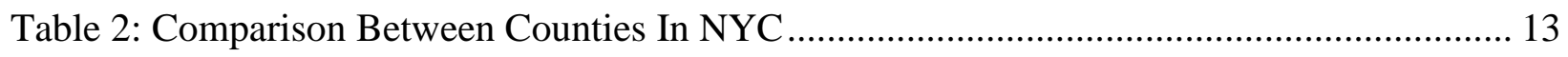

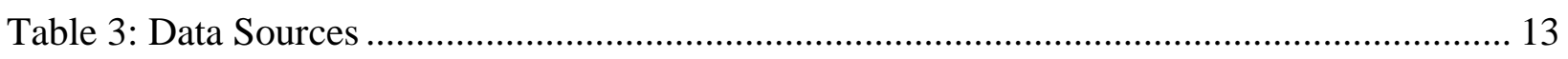

Table 4: Descriptive Statistics Before Transformation....................................................... 19

Table 5: Moran's I Spatial Autocorrelation Results .......................................................... 25

Table 6: Pairwise Multivariant Correlation Results Of The Final Model ................................ 27

Table 7: Diagnostics For Spatial Dependence ...................................................................... 28

Table 8: Result Of The Coefficient Estimates Of The SLM And OLS Model........................... 30 


\section{CHAPTER 1: INTRODUCTION}

The public transportation system in New York City (NYC) is one of the largest transportation systems in the world. The NYC subway system carried about 5.4 million people every weekday of 2018 and nearly 3 million people on weekends (Metropolitan Transit Authority, 2018). Even though much of the NYC population depends on the subway system for their daily commute, the subway ridership has been in decline since 2015. The Metropolitan Transit Authority (MTA) subway ridership totaled about 1.68 billion in 2018 after experiencing a decline of nearly $5 \%$ from 2015 when subway ridership had reached its peak (MTA, 2019). At the same time, NYC has experienced an increasing trend of emerging mobilities including ride-hailing, carpooling, and bicycle sharing services. The mobility survey revealed that the decline in subway ridership may be a result of this rapid increase in emerging mobility services (NYC Mobility Survey, 2018).

Bike sharing programs have become increasingly popular around the world. Over the last decade, many large cities in the United States (US) have followed this trend, experiencing rapid growth of bike sharing programs (Noland et.al., 2016; Zhang et. al., 2019). The NYC bike sharing program, Citi Bike, began in 2013; it maintains sharing stations in all five boroughs of NYC except Staten Island. The Citi Bike program is the largest one of its kind in the US with 864 bike-sharing stations. The number and dispersion of these stations means that people can easily rent or return bicycles from/to these stations using one of the program's electronic fobs or a credit card. The Citi Bike facilitates using bicycles for short and often utilitarian trips within the urban core rather than long recreational trips (Noland et.al., 2016).

The bike sharing program affects subway ridership in a number of ways. As a direct effect, a bike sharing system may substitute or complement existing subway services (Campbell and Brakewood, 2017). When people take short trips using bike sharing instead of subways, it acts as a substitute, decreasing subway ridership. On the other hand, if people use bike sharing services for the first and last mile of a long-distance trip, the service complements the system, leading to an increase in subway ridership. Besides these two scenarios, bike sharing generates recreational trips that may not affect subway ridership. There may also be indirect effects, such as creating bike friendly communities or reducing the load on the public transportation system. The primary objective of the current research is to examine whether there is a relationship between subway ridership and bike sharing programs. To investigate the research questions herein, this study 
considered MTA NYC subway ridership data and subway system characteristics, as well as Citi Bike data. Spatial regression modeling techniques were used to determine the relationship between subway ridership and bikes sharing program. 


\section{CHAPTER 2: LITERATURE REVIEW}

Deploying and promoting transit services compose one of the most effective tools to reduce congestion and enhance access in most cities around the world, where bike sharing has become an emerging mobility option in recent years. Both transit and shared bike services are sustainable modes of transportation. Subways are one of the most prominent transit modes in the many megacities of the world. This research primarily investigates the factors affecting subway ridership, as well as the impact of bike sharing programs on transit ridership.

Several studies investigated the trend in bike sharing services and their relationship with public transportation modes such as subways, bases, rails etc. Pucher et al. (2011) studied the bike sharing trend in nine large cities in North America (i.e., Chicago, Minneapolis, New York City, Portland, San Francisco, Washington DC in US, and Toronto, Vancouver, Montreal in Canada). They found an increasing trend in bike sharing and commuting in all nine cities. Rixey (2013) investigated the effects of demographics and built environment characteristics around bike sharing stations on bike sharing ridership in the Capital Bikeshare, Denver B-Cycle, and Nice Ride MN systems (Rixey, 2013). The author reported that population density, retail job density, presence of bike lanes, income and education positively impacted bike sharing ridership. The study also concluded that proximity to a greater number of other bike sharing stations exhibited a strong positive correlation to bike sharing ridership (Rixey, 2013).

Few studies explored the relationship between transit ridership and bike sharing in recent years. Ma et al. (2015) studied the impact of the Capital Bikeshare (CaBi) program on Metrorail's ridership in Washington, D.C. They developed a linear regression model and reported that public transit ridership was positively associated with $\mathrm{CaBi}$ ridership at the station level. A $10 \%$ increase in annual $\mathrm{CaBi}$ ridership contributed to a $2.8 \%$ increase in average daily Metrorail ridership. Fan et al. (2019) investigated the mode choice behaviors of travelers for first/last mile trips before and after introducing bicycle-sharing systems in Beijing, China. They applied the multinomial logit model to determine travel choice models for first/last mile trips, determining that shared bicycles quickly become the preferred mode over walking. Gender, bicycle availability, and travel frequency were the most significant factors leading up to implementation of bicycle-sharing systems. Additionally, access distance dramatically affects mode choices for first/last mile trips.

In excess of $80 \%$ of transit travelers took walking and shared bicycles as feeder modes. Moreover, 
bike sharing in Beijing China provided first/last mile connectivity for transit. On the contrary, Campbell and Brakewood (2017) found that bike sharing systems negatively impacted bus ridership in NYC; the study used a difference-indifferences identification strategy by dividing the bus routes into control and treatment groups based on whether they were located in areas with bike sharing infrastructure. The study reported a significant decrease in bus ridership along treated routes compared to control routes. The results from the study indicated that every thousand bike sharing docks along a bus route were associated with a $2.42 \%$ fall in daily unlinked bus trips on transit bus routes in Manhattan and Brooklyn. Ma et al. (2015), Fan et al. (2019) and Campbell and Brakewood (2017) research studies reveal that bike sharing's impact on transit may vary based on location and associated land use patterns.

Shaheen et al. (2013) investigated the modal shift of individuals participating in four public bike sharing systems in North America by conducting an online survey of four major bike sharing organizations in Montreal (Canada), Toronto (Canada), the Twin Cities (US), and Washington D.C. (US). The researchers determined that bike sharing enhanced public transportation and improved transit connectivity. With respect to modal shift, results suggested that bike sharing drew from all travel modes. Three largest cities in the study exhibited declines in bus and rail usage owing to bike sharing. For example, $50 \%$ of Montreal respondents reported that they used rail less, while $44 \%$ and $48 \%$ reported similar shifts in Toronto and Washington D.C., respectively. In addition, $27 \%$ to $40 \%$ of respondents reported using public transit in conjunction with bike sharing to complete trips previously conducted by automobile. In the Twin Cities, the dynamics were different, whereupon $15 \%$ of respondents reported increasing rail usage versus only $3 \%$ decreasing their rail usage. Martin and Shaheen (2014) mapped the home locations of survey participants to investigate the relationship between one's habitation location and their mode choice shift. In Washington, D.C., Capital Bikeshare (CaBi) members mostly living in the urban core reported decreasing rail transit use, while those who more likely to live in the urban periphery increased their rail transit use.

Some studies indicate that proximity of a transit station can be a significant factor for a bike sharing program's success. Daddio (2012) found that the number of rail transit stations within a walking distance of $400 \mathrm{~m}$ (1/4 mile) of a bicycle sharing station was a significant (at the $95 \%$ level) factor affecting the use of a bicycle-sharing program. Ma et al. (2015) found that CaBi ridership within 
a $1 / 4$ mile radius of transit stations in Washington D.C. is a significant factor that positively influences transit ridership in the area.

Considering the literature, one can conclude that impact of bike sharing is associated with spatial dependencies. None of the previous studies applied spatial regression techniques to explore the effects of bike sharing programs on subway ridership. The current study adopts a spatial regression model to explain the spatial nature of the relation between MTA subway ridership and the Citi Bike program in NYC. The findings of this research can be used to develop transit and bike oriented transportation policies - this is especially the case in cities where bike sharing programs are becoming more popular. 


\section{CHAPTER 3: DATA AND ANALYSIS}

The Citi Bike program launched in May 2013 and currently offers the largest bike sharing system in the US. NYC Bike Share, LLC operates the bike sharing program. Initially, Citi Bike had only 332 bike sharing stations with 6,000 rental bikes, with stations limited exclusively to Manhattan and Brooklyn. As of December 2019, the bike fleet grew to a total number of 12,800 bikes with bike sharing stations close to one thousand. This research employed station-wise average weekday subway ridership data for the year 2018. Citi Bike station-wise yearly ridership was converted to average daily weekday ridership. The following sections present a descriptive analysis of Citi Bike ridership and other explanatory variables.

\subsection{7-2018 Citi Bike Ridership Data}

This work compared Citi Bike Ridership between December 2017 and December 2018 to observe trends in Citi Bike ridership. Results indicate an increase of about $14.2 \%$ in ridership during this one-year period.

Table 1: Comparison Analysis Between December 2017 Trip Survey And December 2018 Trip Survey For Citi Bike

\begin{tabular}{|l|c|c|}
\hline & Dec 2017 & Dec 2018 \\
\hline Gender & & \\
\hline Male & $73 \%$ & $73 \%$ \\
\hline Female & $22 \%$ & $22 \%$ \\
\hline User type & & \\
\hline Short term customer & $4 \%$ & $6 \%$ \\
\hline Annual subscriber & $96 \%$ & $94 \%$ \\
\hline Age & & \\
\hline $50+$ & $34 \%$ & $21 \%$ \\
\hline $40-50$ & $18 \%$ & $23 \%$ \\
\hline $30-40$ & $26 \%$ & $30 \%$ \\
\hline $20-30$ & $21 \%$ & $25 \%$ \\
\hline$<20$ & $1 \%$ & $1 \%$ \\
\hline Total number of trips & 889,968 & $1,016,507$ \\
\hline Percent growth rate & \multicolumn{2}{|c|}{$14.2 \%$} \\
\hline
\end{tabular}

\subsubsection{Gender Distribution}

Gender distribution of Citi Bike riders shows no difference between 2017 and 2018 (Table 1). In December 2017, the percentages of male and female Citi Bike riders were $73 \%$ and $22 \%$, 
respectively. The data indicates that the male population used Citi Bikes $51 \%$ more than the female population.

\subsubsection{Service Categories}

Citi Bike allows users to buy annual memberships and 3-day, daily or single ride passes. The annual membership program provides the first 45 minutes of the ride cost-free for an unlimited number of rides and an incremental charge per minute following the first 45 minutes. Figure 1 shows the types of users engaging the Citi Bike service. In December 2017, the total number for annual subscribers and short term customers (i.e. 3-day, daily or single ride pass) that used Citi Bike was $96 \%$ and $4 \%$ respectively (represented by the inner circle in Figure 1). The number of short term customers increased by $2 \%$ to $6 \%$ of total users in 2018 (represented by the outer circle in Figure 1). The total number of subscribers and customers in December 2017 for the Citi Bike program were 855,573 and 34,394 in a one-year period; these numbers jumped to 955,408 and 61,097, respectively, in 2018. Annual subscribers experienced a 11.6\% growth versus a $77.6 \%$ growth for short term customers. These facts prove that the Citi Bike program is significantly penetrating the transportation sector and attracting more users.

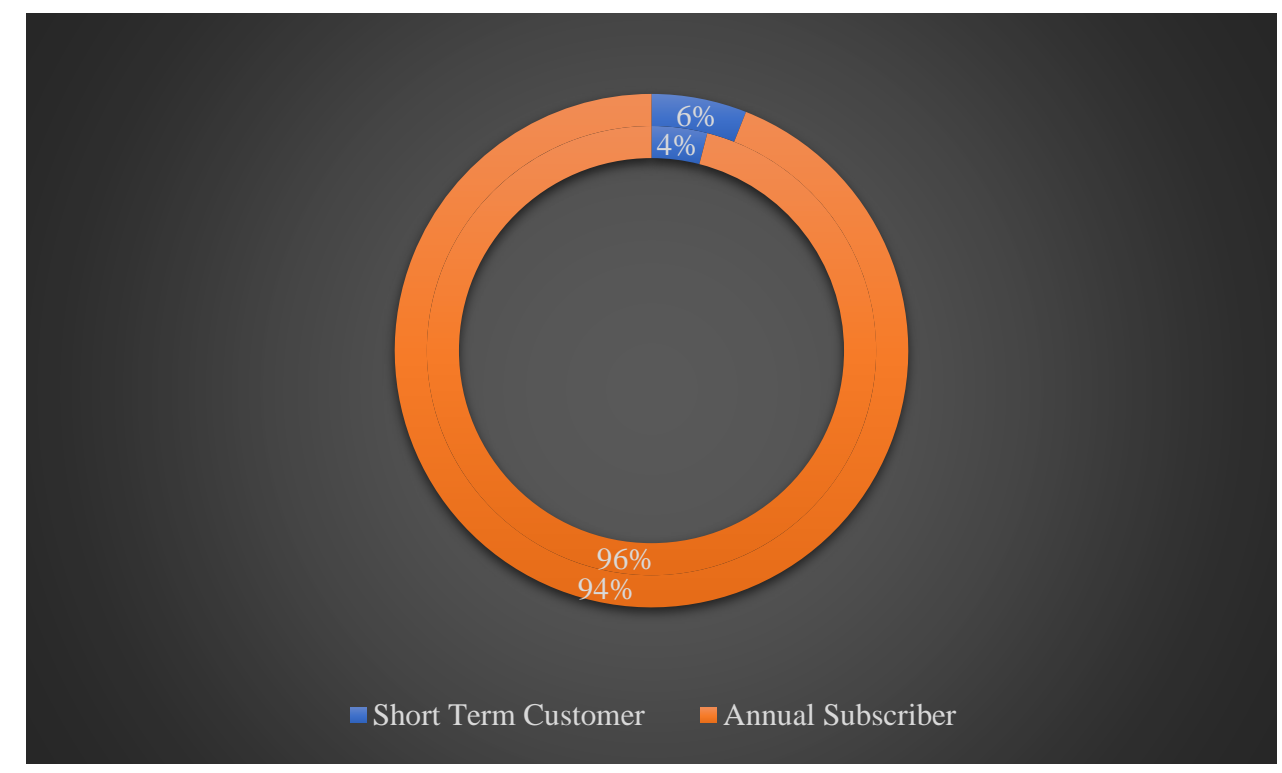

Figure 1: Type Of User Distribution Of Citi Bike Program From 2017-2018 (The Inner Circle Is Citi Bike Distribution In December 2017 And The Outer Circle Reflects Citi Bike Distribution In December 2018) 


\subsubsection{Age Distribution}

Table 1 shows age distribution for Citi Bike riders for both 2017 and 2018. Data indicates that in 2018 more than $50 \%$ of the riders were between the age of 30 and $50,21 \%$ of the riders were seniors (aged 50+), about 25\% of the riders were between 20 and 30 years of age, and only $1 \%$ of riders were 20 years of age or less. This statistic indicates the major age groups of frequent users of Citi Bike; one can use it to develop targeted advertising/marketing initiatives to increase bike sharing services.

\subsection{Socio Demographic Characteristics of NYC}

This section overviews NYC and the difference between its five counties of Manhattan, Kings, Queens, Bronx and Staten Island in terms of socio-demographic characteristics.

\subsubsection{Gender Distribution}

NYC population gender distribution shows the percent of the female population is four percent higher than the male population at 52\% and 48\%, respectively (2018 US Census). Previous analysis showed that the percentage of female users taking trips was significantly lower than the male users in Citi Bike ridership. This situation indicates the difference in travel behavior in male and female users. There is a potential to increase female participation in the bike sharing program by considering their characteristics as a demographic.

\subsubsection{Age Distribution}

Figure 2 presents the age distribution of the NYC population. $45 \%$ of the population in NYC falls within the age distribution of 25 to 54 years. The bike sharing trips also show that these age groups share the majority of bike sharing trips. The highest percentage (18\%) of the population was in the 25 to 34 years age group. 


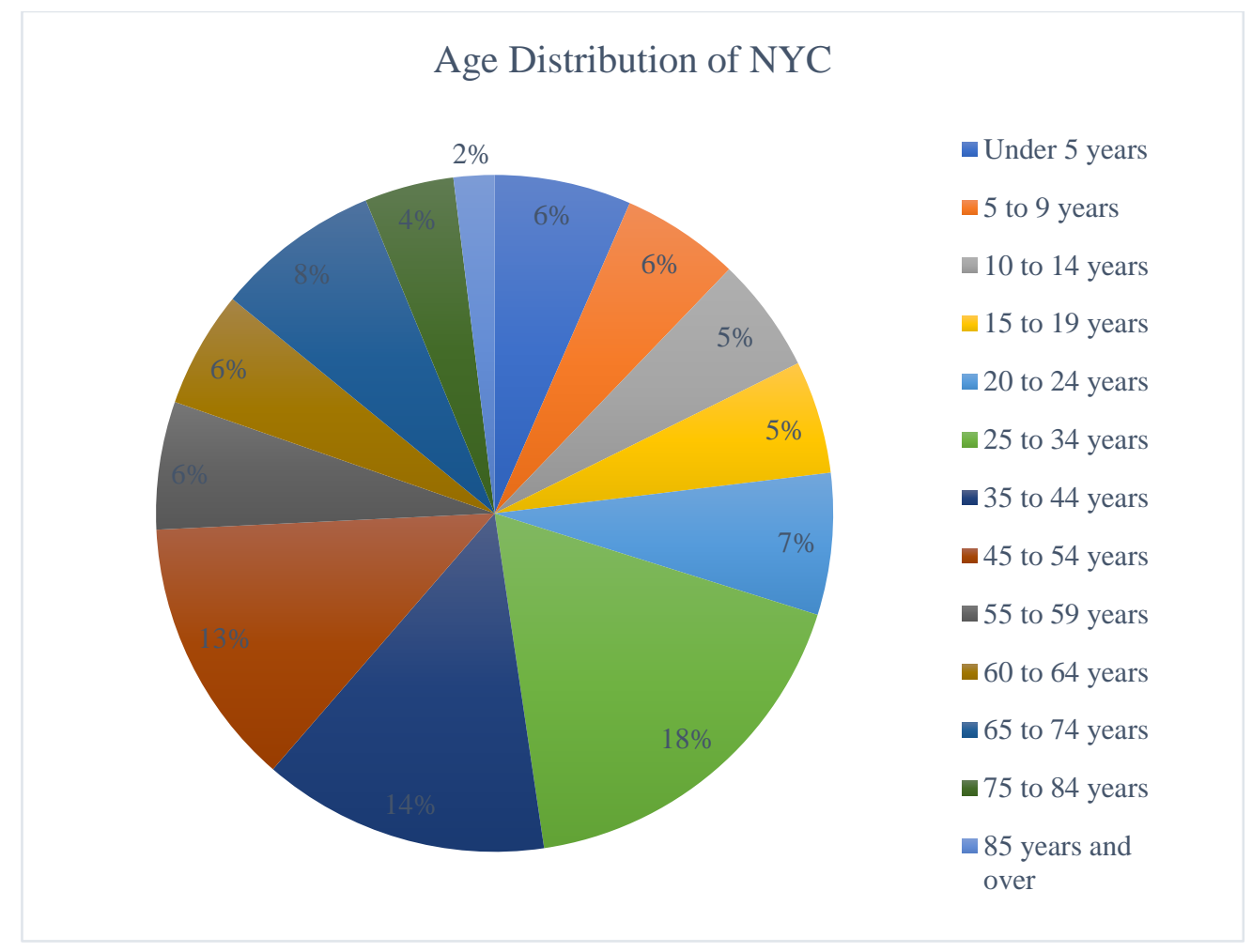

Figure 2: Age Distribution Of NYC Population Based On 2018 US Census

\subsubsection{Population Distribution}

Figure 3 shows the population density per square mile for five counties in NYC. This pattern sheds light on the travel behavioral patterns in the counties, including Citi Bike trips and number of subway ridership. For instance, Kings County is not expected to have a similar number of trips compared to Manhattan County, but instead it is expected to have similar outcomes to Bronx County since Kings and Bronx have similar population density per square mile. Manhattan County is twice as dense as Kings and Bronx per square mile. Moreover, Manhattan County is denser than Staten Island, Queens and Kings combined. Figure 4 shows the population distribution (\%) in NYC by county. Queens and Kings counties have 58\% of the New York City population with $27 \%$ in Queens and 31\% in Kings, while Manhattan has the third largest population. 


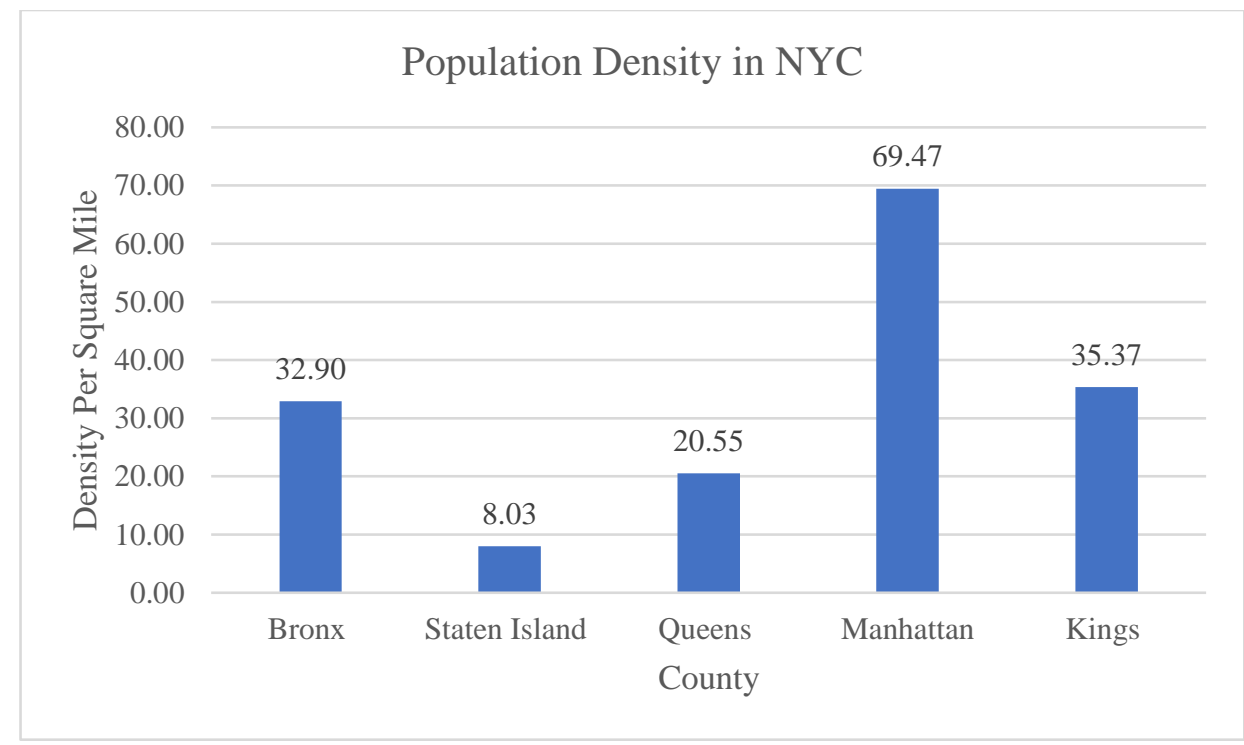

Figure 3: Population Density Of NYC In Square Mile Based On 2010 US Census In Thousands

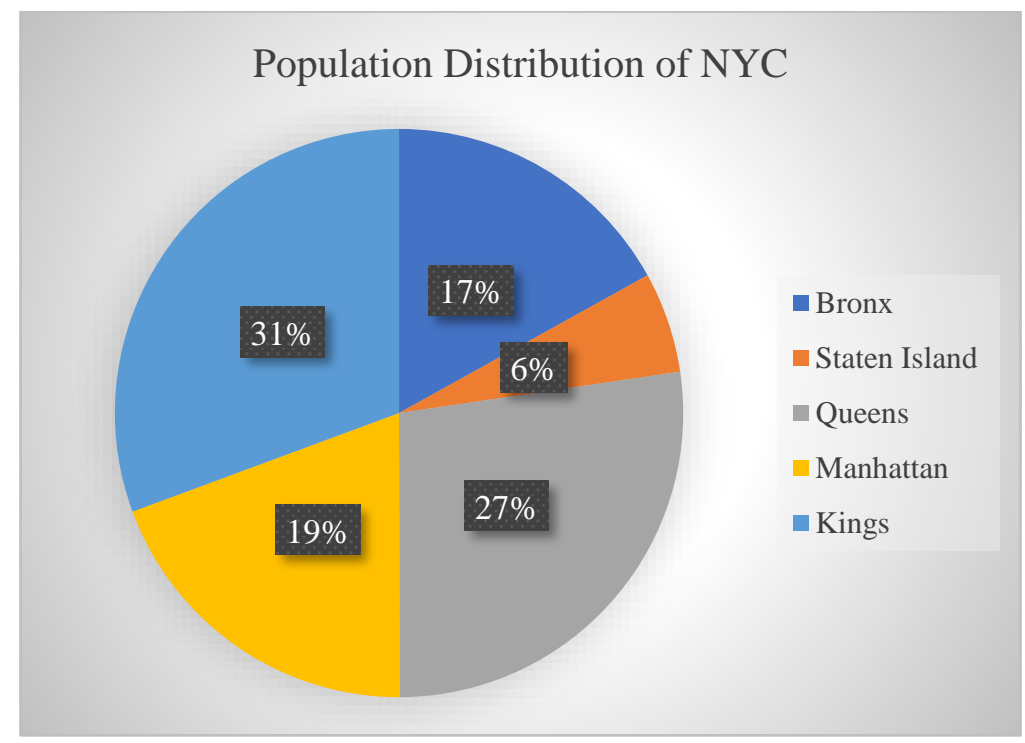

Figure 4: Population Distribution Of NYC Population Based On 2010 US Census

\subsubsection{Housing Density in NYC}

Figure 5 shows the number of housing units per square mile in each county in NYC; Figure 6 shows the percent of total housing units in each county. Kings County occupies the most housing units $(30 \%)$ of all NYC's counties. Bronx County has half the housing units of Kings County (15\%). Staten Island has the lowest number of housing units (5\%). Both Queens and Manhattan counties have $25 \%$ of the total housing units. However, Figure 4 indicates that Queens County 
has $8 \%$ more population than Manhattan. According to NYC DOT, commute trips are much more likely to involve the subway and much less likely to include walking compared to non-commute trips, where commute trips are 10.7 minutes longer on average compared to non-commute trips (NYC, 2018). NYC DOT conducted a phone survey to find the number of total trips started from each county. The survey sample size was 6,063 and resulted in $34 \%, 25 \%, 19 \%, 11 \%, 5 \%, 5 \%$ of total trips correspond to Manhattan, Kings, Queens, Bronx, Staten Island and outside NYC, respectively.

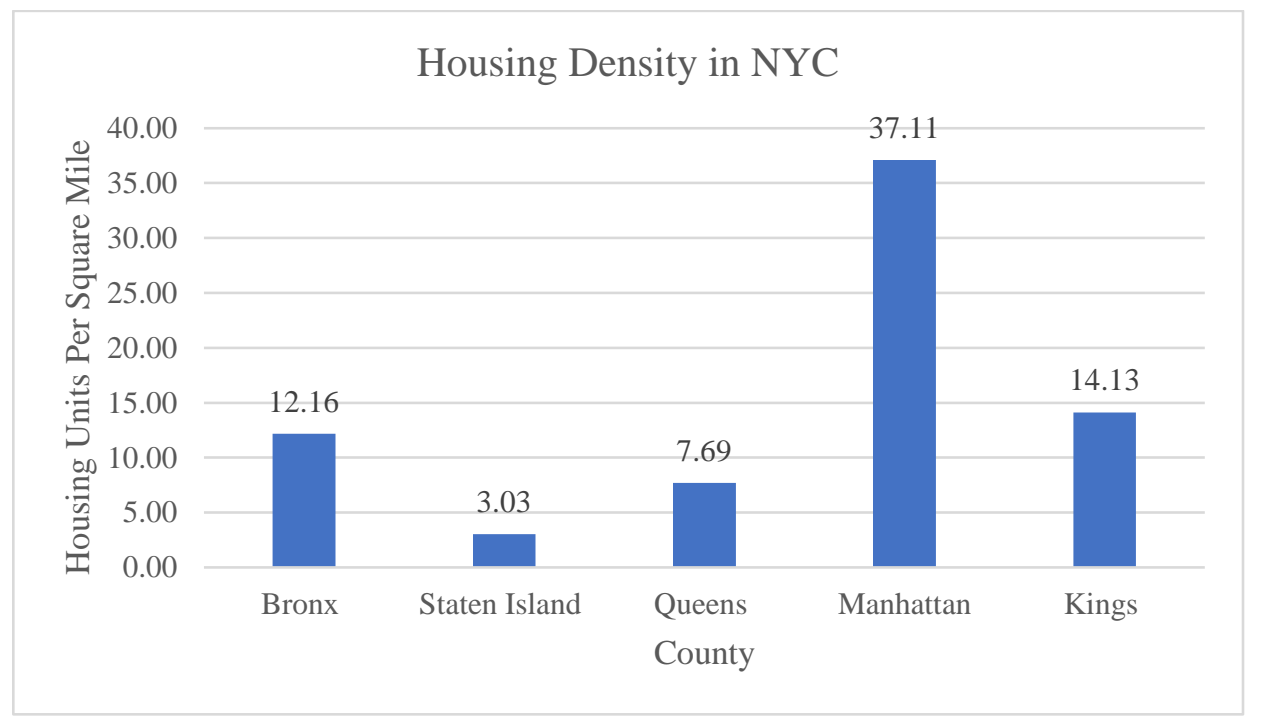

Figure 5 : Housing Density Of NYC Per Square Mile Based On 2010 US Census In Thousands 


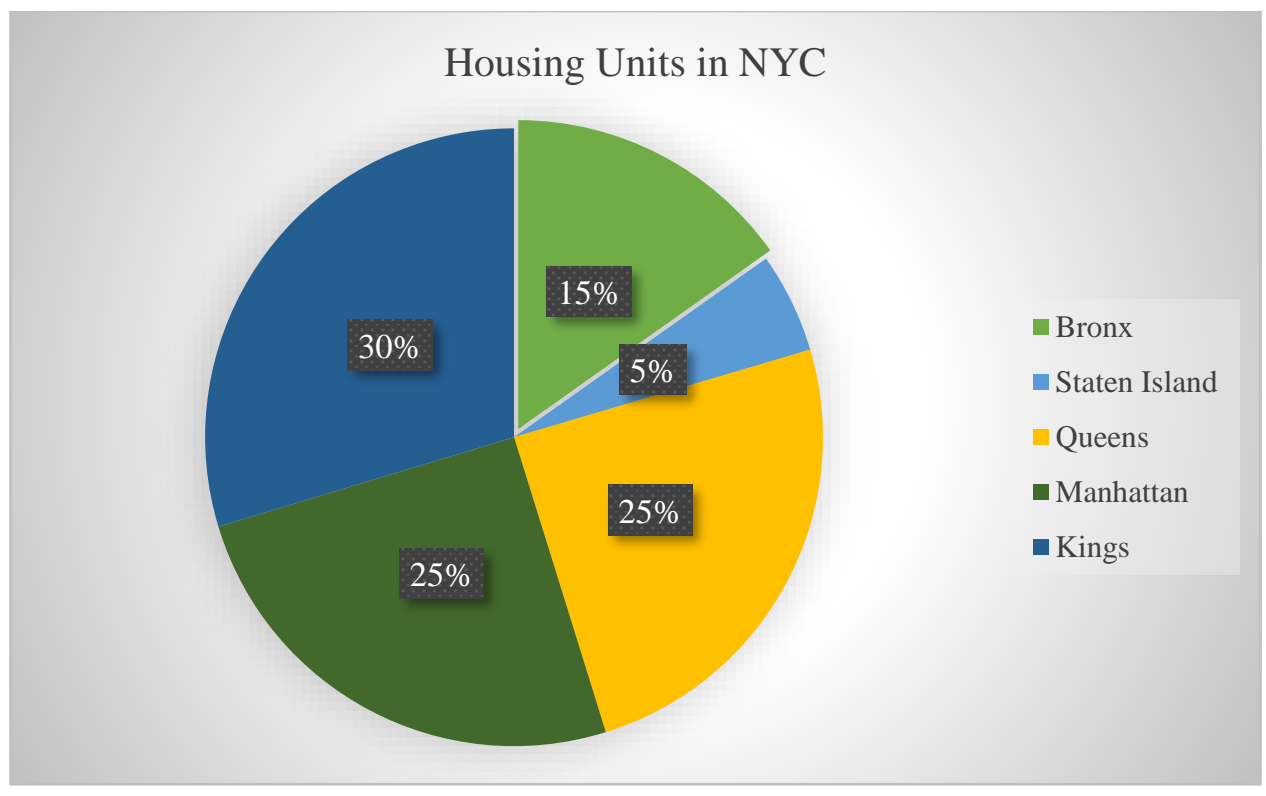

Figure 6 : Housing Units In NYC Population Based On 2010 US Census

\subsubsection{Area of NYC}

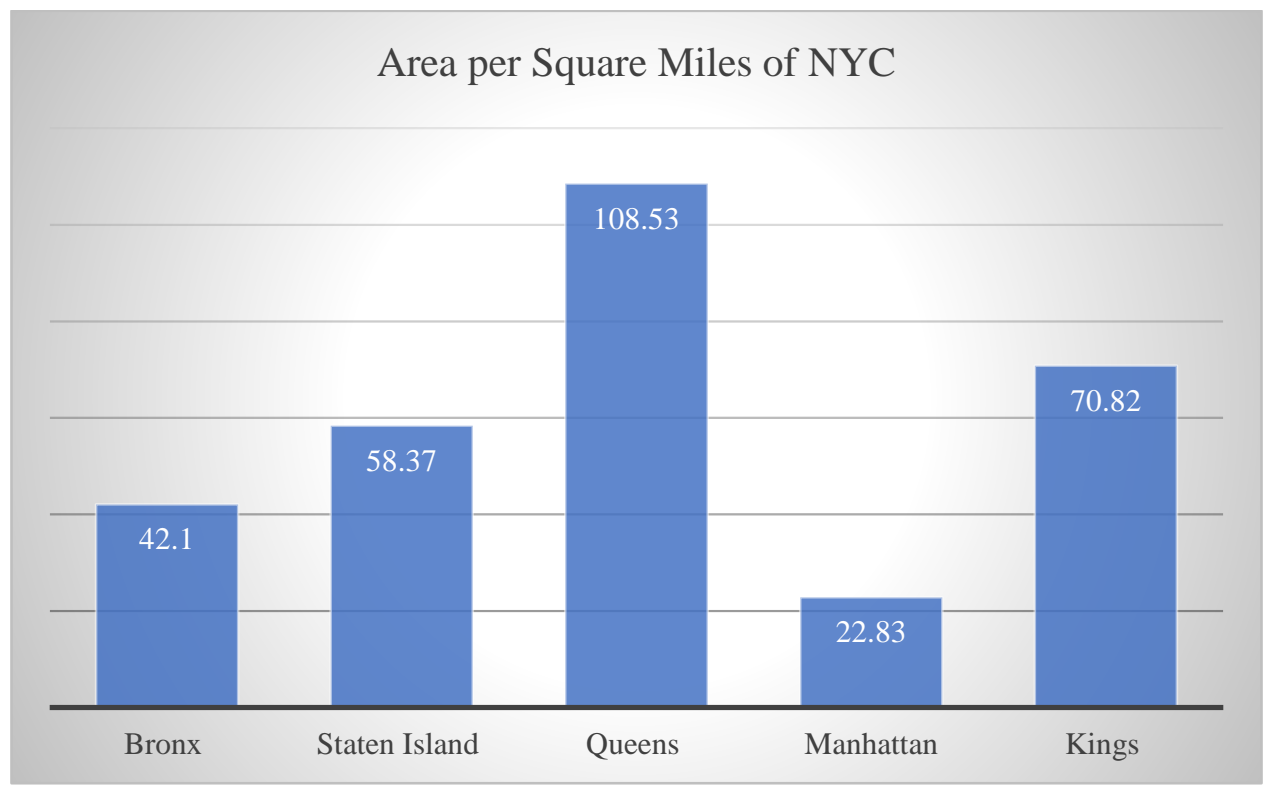

Figure 7: Area In Square Miles Of NYC Population Based On 2010 US Census 
Table 2 summarizes four major characteristics (population density, population distribution, housing density, housing unit) of five counties in NYC. In terms of population density and housing density, Manhattan has the highest density, while Kings County has the highest percentage of population and housing units.

Table 2: Comparison Between Counties In NYC

\begin{tabular}{|l|l|l|l|l|l|}
\hline County & Manhattan & Bronx & Kings & Queens & $\begin{array}{l}\text { Staten } \\
\text { Island }\end{array}$ \\
\hline $\begin{array}{l}\text { Population Density } \\
\text { in Square mile }\end{array}$ & $\mathbf{6 9 . 4 7}$ & 32.90 & 35.37 & 20.55 & 8.03 \\
\hline $\begin{array}{l}\text { Population } \\
\text { Distribution }\end{array}$ & $19 \%$ & $17 \%$ & $\mathbf{3 1 \%}$ & $27 \%$ & $6 \%$ \\
\hline $\begin{array}{l}\text { Housing density in } \\
\text { Square mile }\end{array}$ & $\mathbf{3 7 . 1 1}$ & 12.16 & 14.13 & 7.69 & 3.03 \\
\hline Housing units & $25 \%$ & $15 \%$ & $\mathbf{3 0 \%}$ & $25 \%$ & $5 \%$ \\
\hline
\end{tabular}

\subsection{Modeling Variables used in this Research}

This section is divided into two sections: section 3.3.1 discusses the dependent variable (subway ridership's) and section 3.3.2 addresses all independent variables.

The software used to aggregate the dependent and the explanatory variables within $1 / 4$ mile radius was QGIS.

Table 3: Data Sources

\begin{tabular}{|l|l|l|}
\hline Dependent Variable & Definition & Data Source \\
\hline Subway Station Ridership & $\begin{array}{l}\text { Average Weekday } \\
\text { Ridership }\end{array}$ & $\begin{array}{l}\text { Metropolitan Transportation } \\
\text { Authority (MTA) }\end{array}$ \\
\hline Explanatory Variables & $\begin{array}{l}\text { Longitudinal and } \\
\text { Latitudinal } \\
\text { Coordinates }\end{array}$ & NYC Open Data \\
\hline Subway Station Location & Citi Bike Ridership & Citi Bike Official Website \\
\hline Citi Bike Ridership & &
\end{tabular}




\begin{tabular}{|c|c|c|}
\hline Number of Citi Bike Stations & $\begin{array}{l}\text { Number of Citi Bike } \\
\text { Station }\end{array}$ & Citi Bike Official Website \\
\hline White Population & $\begin{array}{l}\text { Number White } \\
\text { Population }\end{array}$ & $\begin{array}{l}\text { USA Population Density ArcGIS } \\
\text { Data Census Tract Level }\end{array}$ \\
\hline African American Population & $\begin{array}{l}\text { Number African } \\
\text { American Population }\end{array}$ & $\begin{array}{l}\text { USA Population Density ArcGIS } \\
\text { Data Census Tract Level }\end{array}$ \\
\hline Asian Population & $\begin{array}{l}\text { Number Asian } \\
\text { Population }\end{array}$ & $\begin{array}{l}\text { USA Population Density ArcGIS } \\
\text { Data Census Tract Level }\end{array}$ \\
\hline Employment Rate & Employment Rate & $\begin{array}{l}\text { USA Population Density ArcGIS } \\
\text { Data Census Tract Level }\end{array}$ \\
\hline $\begin{array}{l}\text { Median Family and Nonfamily } \\
\text { Household Income }\end{array}$ & Median Income & $\begin{array}{l}\text { ACS } 5 \text { Year Socioeconomic Data } \\
\text { By Tract 2008-2012 }\end{array}$ \\
\hline Number of Bus Stations & Bus Stop & NYC Open Data \\
\hline Number of Jobs & Number of Jobs & U.S. Census Bureau \\
\hline Poverty Rate & $\begin{array}{l}\text { Poverty Rate by } \\
\text { County }\end{array}$ & Poverty USA \\
\hline $\begin{array}{l}\text { Number of People Without } \\
\text { Driving Licenses }\end{array}$ & $\begin{array}{l}\text { Number of Driving } \\
\text { Licenses }\end{array}$ & NYC DMV \\
\hline $\begin{array}{l}\text { Number of People Without } \\
\text { Vehicle }\end{array}$ & $\begin{array}{l}\text { Number of Registered } \\
\text { Vehicles }\end{array}$ & NYC DMV \\
\hline $\begin{array}{l}\text { Population Per Square Mile In } \\
\text { NYC }\end{array}$ & $\begin{array}{l}\text { Population Per Square } \\
\text { Mile } 2010\end{array}$ & U.S. Census Bureau \\
\hline
\end{tabular}

\subsubsection{Dependent Variable}

The subway stations' geographic locations were collected from the NYC open data portal (Open Data, N. 2020a) and the station-wise weekday ridership data was collected from the Metropolitan Transportation Authority (MTA) website (web.mta.info). The dependent variable (subway ridership) is the average weekday departures for 2018. Figure 8 shows the locations of the subway stations. To estimate population living within each station influence area, a buffer of 
1/4 mile radius around each subway station were used within he QGIS software, as most users would walk to access the subway within a quarter-mile walking distance (Figure 10) (Noland et al., 2016).

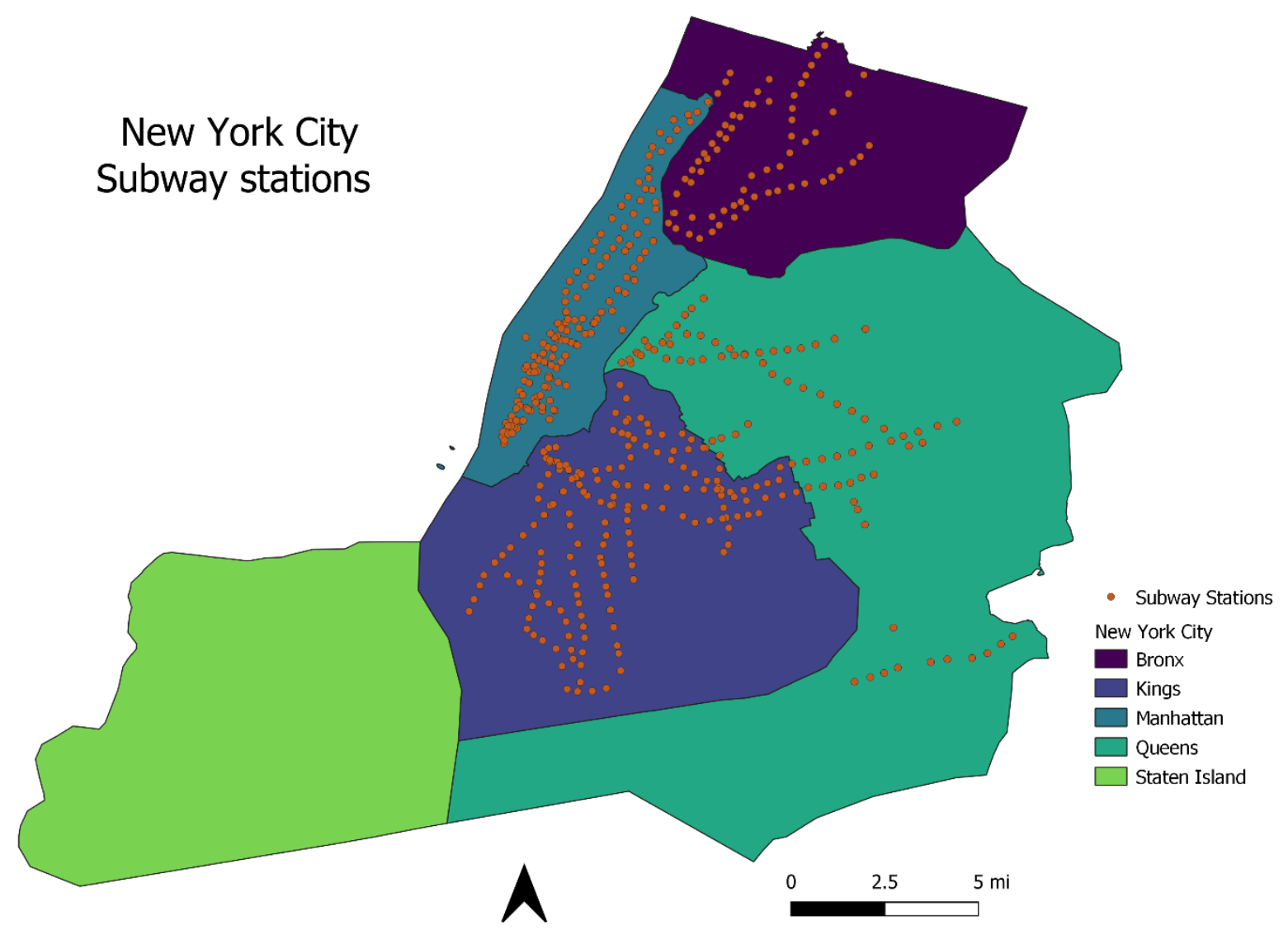

Figure 8: NYC Subway Stations 


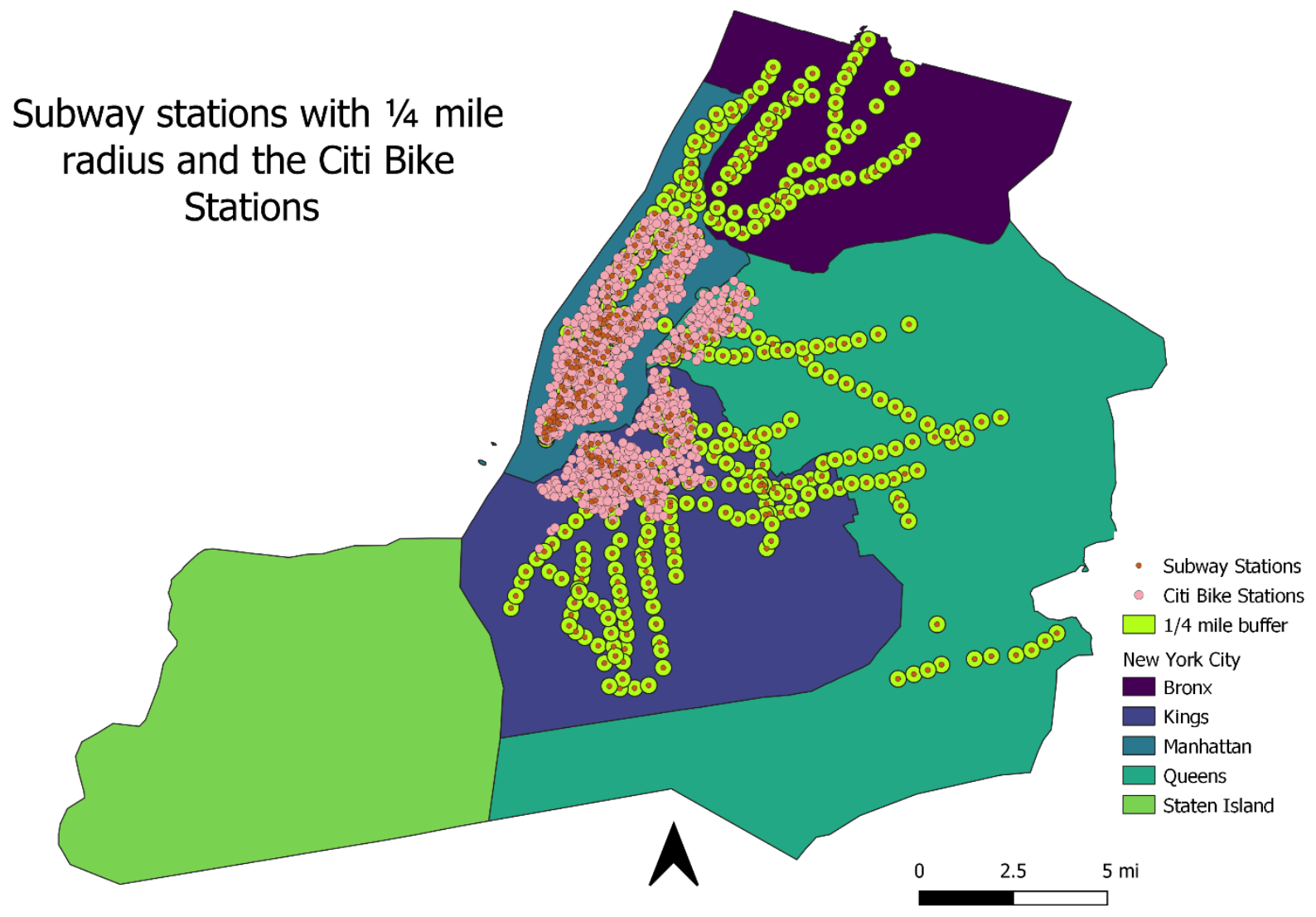

Figure 9: Subway Station With 1/4 Mile Radius And The Citi Bike Station In Accordance To 2018 Trip Survey

\subsubsection{Independent Variables}

\subsubsection{Station Characteristics}

The stations were classified as beginning/end or transfer subway stations. If a station i used for transfers, then it was classified as a transfer station. If the station is located at the end of the line then it was called an end station.

\subsubsection{Citi Bike Variables}

The Citi Bike data was obtained from the official Citi Bike website (Citi Bike NYC. 2020 ). The data contains station IDs and longitudinal and latitudinal coordinates. The chosen stations were those that were in the travel survey of December 2018. The ridership data was collected for 12 months in 2018. The longitudinal and latitudinal coordinates of the chosen stations were plotted using QGIS software. Then number of Citi Bike Stations, the existence of Citi Bike, the number 
of riders were collected. Citi Bike stations were distributed in Manhattan, Kings, and Queens counties, leading to the exclusion of Bronx and Staten Island from further analysis. The Citi Bike ridership variable in this study is the average weekday departures for 2018 , and the study used the Citi Bike departure stations. Figure 10 indicates the locations of Citi Bike stations in the NYC area.

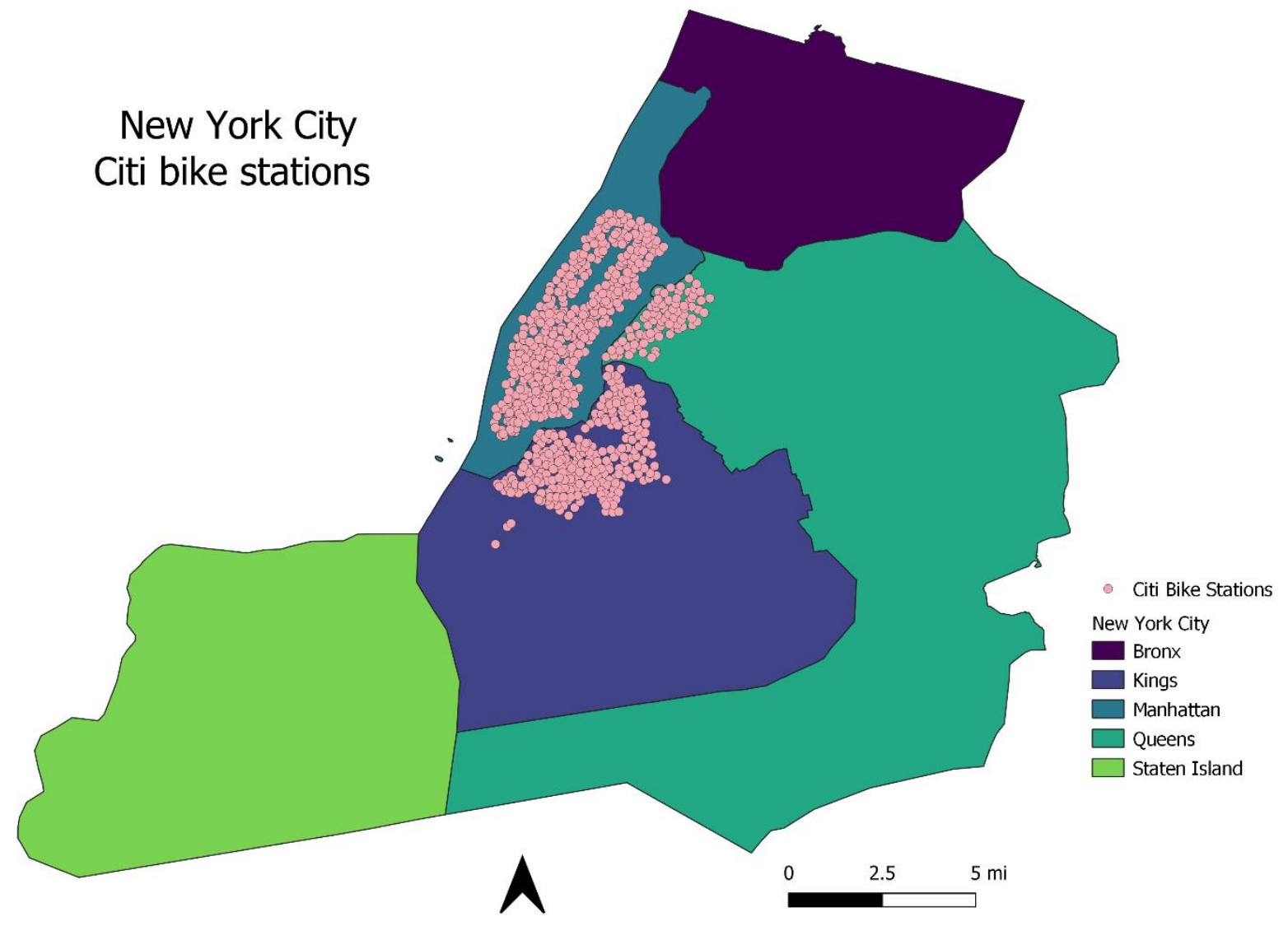

Figure 10: Citi Bike Stations In NYC According To The 2018 Trip Survey

\subsubsection{Socio-demographic Variables}

Using ArcGIS data, the study collected information on the census tract level population, housing units, average household size, $\%$ male, $\%$ female, white population, African American population, Asian population, unemployment rate data for the year 2012 (USA Population Density. Arcgis. 2020). Those data were plotted and combined with the subway station data on QGIS software. 
The total numbers of the population with no vehicle and no driving licenses were obtained from the NYC Department of Motor Vehicles (DMV) (Archives of Statistical Summaries. New York DMV. 2020). Those two variables were calculated per county. For the population with no vehicle variable, the total number of registered vehicles obtained from the NYC DMV was subtracted from the total population. The process for the population with no driving licenses was as follows: the total number population with driving licenses was subtracted from the total population to obtain the total population with no driving licenses. To ensure consistency with the population estimate from the ArcGIS hub boundary tract, the number of registered vehicles and driving licenses are from 2012.

Median family household income and median non-family household (single) income were obtained from the Berkeley library geo data website (ACS 5 Year Socioeconomic Data Tract, 2. 2020). The file in the library is the ACS 5 Year Socioeconomic Data by Tract 2008-2012. Total number of jobs derive from the US Census Bureau (Bureau, U. 2020). The number of bus stations was obtained from the NYC open data website (Open Data, N. 2020b). The study obtained the poverty rate from (Maps \& Data. 2020). The study calculated the poverty rate by county. Table 4 summarizes the basic descriptive statistics of dependent and independent variables. 
Table 4: Descriptive Statistics Before Transformation

\begin{tabular}{|l|r|r|r|r|}
\hline & Mean & Std. dev & Min & Max \\
\hline Subway ridership (average weekday) & 18600 & 17184.646 & 2782 & 103572 \\
\hline Number of Citi Bike stations (count) & 5 & 1.792 & 1 & 8 \\
\hline Citi bike ridership (average weekday) & 435 & 681.036 & 8 & 4573 \\
\hline Housing units (count/block) & 3587 & 1582.865 & 1480 & 8882 \\
\hline Average household size (average/ block) & 2.5 & 0.846 & 1.71 & 5.65 \\
\hline African American population (percent/block) & 0.198 & 0.217 & 0.012 & 0.845 \\
\hline Asian population (percent/block) & 0.162 & 0.161 & 0.012 & 0.805 \\
\hline Unemployment rate per block & 17.996 & 6.876 & 8.7 & 47.5 \\
\hline Median household income per block & 116626 & 45707.92 & 42125 & 243622 \\
\hline Number of jobs (count) & 35 & 14.967 & 0 & 110 \\
\hline Number of bus station (count) & 6 & 4.016 & 0 & 17 \\
\hline People with No Driving Licenses per county & 1531046 & 381008.475 & 1232075 & 2052635 \\
\hline & & Frequency & & \\
\hline End station & 0 & 49 & & \\
\cline { 2 - 6 } & 1 & 32 & & \\
\hline Transfer stations & 0 & 115 & & \\
\cline { 2 - 6 } & 1 & 11 & & \\
\hline
\end{tabular}

1. Note: $\mathrm{n}=126$

2. For end stations, 0 means not end stations and 1 means end station. The same for transfer stations. 


\section{CHAPTER 4: METHODOLOGY}

Spatial regression models were used to incorporate the spatial dependency between the subway stations and other independent variables in the current study. Besides applying the spatial regression model, the current study performed an ordinary least square (OLS) regression to compare the models. Before proceeding with the modeling, the study conducted tests to determine the distribution of the dependent variables, correlations between the independent variables, and outliers in the data. The researcher considered different combinations of the independent variables so as to select the best combination of independent variables. A Shapiro-Wilks normality test on subway ridership data (the dependent variable) showed that the subway ridership was abnormally distributed. Furthermore, the data exhibited a high variation, leading to the log transformation for normalization. Variables such as the number of Citi Bike stations and the African American population, Asian population, unemployment rate and number of bus stations were kept without any transformation, since the variable falls within range of the other variables. Next, a Multivariate Correlation Analysis was performed to find the correlation among the independent variables. Only variables with a Variance Inflation Factor (VIF) that was higher than 30 were eliminated. The variables with the lowest correlation with the dependent variable was eliminated and the variable with the higher correlation was kept. Highly correlated variables with correlation coefficients above 0.7 were kept in the model if the VIF was less than 30. The Multivariant Correlation Analysis was done in JMP pro. The OLS model and the spatial regression models were performed in geographic data (GeoDa) analysis software developed by Dr. Luc Anselin and his team. GeoDa provides a graphical interface to methods of explanatory spatial data analysis such as spatial regression analysis for point and polygon data, accessible at geodacenter.github.io. The current study used the program to develop a weight matrix called a Queen spatial weight matrix to perform the analysis. For spatial regression, only the Spatial Lag model was applied in this research.

\subsection{Measures of Spatial Autocorrelation}

Global Moran's I and local Moran's I are two measures of spatial autocorrelation that examine spatial dependence and heterogeneity at a given spatial scale. This study performed univariate global Moran's I to test spatial autocorrelation. The mathematical expression of the Global Morans' I is as follows (Siddiqui et al., 2012): 


$$
\text { Global Moran's } I=\frac{n \sum_{i=1}^{n} \sum_{i=1}^{n} W_{i j}(y[i]-\bar{y})(y[j]-\bar{y})}{\left(\sum_{i \neq j}^{n} \sum_{j=1}^{n} W_{i j}\right)\left(\sum_{i=1}^{n}(y[i]-\bar{y})^{2}\right.}
$$

Where $\mathrm{n}=$ total number of observations and $\bar{y}$ is the mean of $\mathrm{y}[\mathrm{I}]$ 's. Global I ranges between -1 and +1 . Higher positive values are associated with higher degrees of spatial clustering of similar values, while negative values indicate spatial dispersion. The significance of the global I was tested based on the Z-scores (Siddiqui et al., 2012):

$$
Z(I)=\frac{I-E(I)}{S(I)}
$$

Where $\mathrm{E}(\mathrm{I})$ and $\mathrm{S}(\mathrm{I})$ are the expected value and standard deviation of $\mathrm{I} . Z>2.58(1.96)$ indicates positive autocorrelation at the confidence of $99 \%(95 \%)$ - i.e. the existence of either high-value or low-value clustering (Fang et. al., 2015). When spatial correlation is present in the data, a spatial error term in the modeling is necessary to account for unobserved heterogeneity ( Siddiqui et. al., 2012).

\subsection{Creating Weight Matrix}

For the spatial analysis, the relationship between the subway stations were considered by creating a spatial weight matrix. To create the weight matrix, this research assumed that subway stations in close proximity to one another influence each other's ridership more compared to the subway stations that are far apart. Different methods, such as contiguity- or distance-based methods can be used to select neighboring subway stations. Weights are also important during creation of spatially explicit variables (Anselin, 2020a, b). This study used queen contiguity-based weight matrix for modeling the spatial autocorrelation. In a queen contiguity-based method, two spatial units are neighbors when they share a common edge or vertex (Anselin, 2020b). Queen weight matrix works like a distance band when the order of neighborhood is specified. The order of neighborhood sets up the limit of distance band. This study used the first order neighborhood, which connects the spatial unit to the nearest neighbors. The spatial units that have a common vertex are connected. Applying the queen contiguity-based method, the study created an $n \times n$ matrix where $\mathrm{n}$ is the total number of subway stations. Equation 5 represents the weight matrix $\mathrm{W}$ :

$$
W=\left[\begin{array}{ccc}
w_{11} & \cdots & w_{1 n} \\
\vdots & \ddots & \vdots \\
w_{n 1} & \cdots & w_{n n}
\end{array}\right]
$$


In this equation, elements $w_{i j}$ of the matrix are the spatial weights. The spatial weights $w_{i j}$ are non-zero when the subway station $i$ and $j$ are neighbors, and zero if they are far apart.

\subsection{Ordinary Least Squares (OLS)}

The Ordinary Least Squares (OLS) regression model is one of the most commonly used models in statistical modeling, including the field of transportation engineering. The model inherently assumes a linear relationship between the dependent variable and each of the explanatory/independent variables. The OLS model can be expressed as follows (Washington et al., 2011):

$$
Y_{i}=\beta_{0}+\beta_{i} X_{i}+\varepsilon_{i}
$$

In Eq. (1), $Y_{i}$ is the dependent variable, $\beta_{0}$ is the constant term or y intercept, $\beta_{i}$ is the vector of parameter estimates for the independent variables $\left(X_{i}\right)$ and $\varepsilon_{i}$ is the disturbance or error term for observation i.

\subsection{Spatial Lag Model (SLM)}

In an OLS regression model, spatial dependence can be incorporated in two distinct ways: as a spatially lagged dependent variable (Wy) or in the error/disturbance term $\varepsilon$. The spatial model with spatially lagged dependent variable (Wy) is called a Spatial Lag Model (SLM). An SLM is also known as a Spatial Autoregressive Lag Model (SAR). When a spatial model is considered, the error/ disturbance term gets smaller, while the error may become zero if the model explains the interaction well. In an SLM model, one assumed the endogenous variable to be dependent on nearby units (Lambert et al., 2010). The SLM is suited as the focus of the study is to see the existence of a spatial relationship and verify the interaction's strength (Anselin, 2001). The objective of this research is to identify and verify the spatial relationship between subway ridership and Citi Bike ridership and other explanatory variables, as well as the strength of those interactions. Spatial interactions are modeled as weighted average of neighboring observations. In this research, the subway ridership of one station to be spatially dependent on nearby stations ridership was assumed. Thus, the linear SLM model takes the following form (Equation 6):

$$
Y_{i}=\rho W_{y}+X \beta+\varepsilon
$$


Where, $Y_{i}$ is the NYC average daily subway ridership, $W_{y}$ is the spatially lagged weights matrix. W used in GeoDa Software as explained earlier with queen spatial weight matrix. $X$ is the matrix of observations on the exogenous variable, $\varepsilon$ is the vector of error terms or the disturbance, and $\beta$ is the estimated parameters for exogenous variables. In Eq. (6), $\rho$ is an autoregressive coefficient. The spatial lag $\rho$ is a variable that averages the neighboring values of a location, and it therefore accounts for autocorrelation in the model with the weight's matrix. The key component that makes an OLS regression model inconsistent and biased is the spatial lag term. The spatial lag term must be treated as endogenous, and it must have a proper estimation to account for this endogeneity (Anselin, 2001). For an SLM model, the spatially lagged dependent variable is the weighted average of the neighboring subway stations' ridership. Formally, for subway station $i$, the spatial lag of $y_{i}$ is referred to as $[W y]_{i}$ which is expressible in equation 7 (Anselin, 2018).

$$
[W y]_{i}=\sum_{j=1}^{n} w_{i j} y_{j}
$$

The spatial lag is a weighted sum of the values observed at neighboring stations because the nonneighbors have a weight value of zero in the weight matrix.

\subsection{Spatial Error Model (SEM)}

In the Spatial Error Model (SEM), spatial dependence in regression disturbance term is referred to as nuisance dependence (Anselin, 2003). This form of spatial model is most appropriate when it is needed to correct for any potential biasing influence of autocorrelation due to spatial data (Anselin, 2003). Instead of spatially lagged dependent variable, the error term is assumed to be spatially autocorrelated in SEM. The SEM with a spatial autoregressive error term is shown in equation 8 (Murack, 2020).

$$
Y_{i}=\beta_{0}+\beta X+\varepsilon, \varepsilon=\lambda W \varepsilon+u
$$

In equation $8, \beta_{0}$ is the intercept, $\beta$ is the estimated parameters for independent variables, $X$ is a matrix of observations on the explanatory variables, and $\varepsilon$ is a vector of spatially autocorrelated error terms. In the error term, $\mathrm{u}$ is a vector of independent identically distributed errors, $W$ is the spatial weight matrix similar to the weight matrix generated during the spatial lag model, $\lambda$ is nuisance parameter and it is an estimate of the lagged error. Like SLM, nuisance parameter accounts for autocorrelation in the error term. The difference between the lag and error models is 
that $\rho$, the spatial lagged term, is based on the parameters of interest while $\lambda$ is based on the lagged error. The OLS remains unbiased but the standard error term is biased (Anselin, 2003).

\subsection{Model performance Evaluation}

Akaike Information Criteria (AIC), Log-Likelihood and R-squared values are some of the goodness-of-fit measures, which are used in this study. R-square measures how well a particular combination of covariates explains station-wise subway ridership (Dong et al., 2016). Although R-square values for spatial regression models are biased owing to their violation of the assumptions of independent error terms for observations rather than autocorrelated error terms, this study uses R-square as an approximate measure of model fitting (Song et al., 2014). Equation (9) expresses the R-square values:

$$
R^{2}=\frac{\sum\left(y_{i}^{o b s}-y_{i}^{p r e d}\right)^{2}}{\sum\left(y_{i}^{o b s}-\bar{y}_{i}\right)^{2}}
$$

As spatial regression models use a Maximum Likelihood Method (MLE), log-likelihood is commonly used to compare the goodness-of-fit of spatial models. For log likelihood, higher value means better fit of the model. When models are not nested, AIC values can also be used to compare the performance of the models based on how well the model fits the data without overfitting it. It not only considers overall fit of the model but also considers the complexity of the models (Burnham and Anderson, 2004). The AIC value can be computed by the following equation 10-

$$
A I C=-2(\log -\text { likelihood })+2 k
$$

Where, $k$ is the number of model parameters including the intercept and loglikelihood is the measure of model fit. When comparing with other models, lower AIC value means better goodness of fit. 


\section{CHAPTER 5: RESULTS AND DISCUSSION}

Neighboring stations' characteristics (i.e., the subway ridership data tends to be spatially autocorrelated) influence the ridership of one subway station. The preliminary analysis for spatial autocorrelation in the distribution of different dependent and independent variables were carried out by applying the Global Moran's I test. The Moran's test is based on an inferential statistic, where the null hypothesis is that there is no correlation in the data and the alternative hypothesis is that correlation does exist. A univariant Moran's I test determines the spatial relationship between subway station at location $i$ with its neighboring subway stations. Table 5 summarizes the results of the univariant Moran's I test, showing that most of the variables were spatially clustered. This means that, instead of the OLS regression model, the spatial regression model is better suited to explain the spatial dependencies of subway ridership among the subway stations.

Table 5: Moran's I Spatial Autocorrelation Results

\begin{tabular}{|l|c|c|c|}
\hline \multicolumn{1}{|c|}{ Variables } & Univariant Moran's I & Z-Score & Clustering \\
\hline Log (Subway Ridership) & 0.402 & 7.6492 & Clustered \\
\hline Number of Citi Bike Stations & 0.330 & 6.2990 & Clustered \\
\hline Log (Citi Bike Ridership) & 0.635 & 12.0151 & Clustered \\
\hline Log (Housing units) & 0.557 & 10.5816 & Clustered \\
\hline Log (Average Household Size) & 0.637 & 12.1419 & Clustered \\
\hline African American Population & 0.718 & 13.6414 & Clustered \\
\hline Asian Population & 0.537 & 10.4254 & Clustered \\
\hline Log (Median Household Income) & 0.647 & 12.1774 & Clustered \\
\hline Log (Number of Jobs) & 0.148 & 3.1366 & Clustered \\
\hline Number of Bus Stops & 0.311 & 5.9424 & Clustered \\
\hline Log (People with No Driving Licenses) & 0.889 & 16.6760 & Clustered \\
\hline Unemployment Rate & 0.368 & 7.1737 & Clustered \\
\hline
\end{tabular}

Table 6 exhibits the results from the Multivariant Correlation Analysis for the variables (both independent and dependent). Citi Bike ridership had a positive correlation the with subway ridership and the correlation coefficient and p-value of (0.5) and $<0.0001$ at the $95 \%$ confidence level, respectively. This indicates that subway riders harness Citi Bike to connect to subway 
stations. Other studies determined the same positive correlation between the bike system and the transit system (Ma et al., 2015), reflecting similar use purpose to the bike system. The number of Citi Bike stations positively correlated (0.38) with the subway ridership with significance of $<0.0001$ at a $95 \%$ confidence level.

Housing units had a positive correlation (0.46) with subway ridership with a p-value of $<0.0001$ at the $95 \%$ confidence level. This is unlike average household size, which has a (-0.58) correlation with a p-value of $<0.0001$ at a 95\% confidence level. Table 6 shows that the African American population was negatively associated with the subway, indicating that when African American population increase the subway ridership is more likely going to decrease. The African American population had a (-0.32) correlation with subway users and p-value of 0.0002 at $95 \%$ confidence level. However, the Asian population had a positive correlation of (0.15) with subway ridership and a p-value of 0.1025 at the $95 \%$ confidence level, which means that Asian population were less likely to use the subway. Asian population was insignifacnt at $95 \%$ confidance level.

Unemployment rate had correlation of (0.09), which was insignificant at a 95\% confidence level, $\mathrm{p}$ value of (0.3089). Median household income had (0.41) correlation with subway ridership at a $95 \%$ confidence level, $\mathrm{p}$-value $<0.0001$. this indicant when the Median household income increase the subway ridership is more likely going to increase. Both the number of jobs and the number bus stations had a positive correlation of $(0.21)$ and (0.35), respectively, with a p-value at the $95 \%$ confidence level of 0.0193 and $<0.0001$, respectively, with subway ridership. This means that some bus transit passengers had been using the bus as to complement their route and help reach the subway, and that more jobs means a likely increase in subway ridership. The people with no driving licenses had a negative correlation (-0.58) with p-value of $<0.0001$ at a $95 \%$ confidence level. 
Table 6: Pairwise Multivariant Correlation Results Of The Final Model

\begin{tabular}{|c|c|c|c|c|c|c|c|c|c|c|c|c|c|}
\hline Log (Subway Ridership) & 1 & 0.38 & 0.5 & 0.46 & -0.58 & 0.16 & -0.32 & 0.15 & 0.09 & 0.41 & 0.21 & 0.35 & -0.58 \\
\hline Number Citi Bike stations & & 1 & 0.69 & 0.39 & -0.42 & 0.25 & -0.26 & 0.09 & -0.03 & 0.43 & 0.32 & 0.14 & -0.43 \\
\hline Log (Citi Bike Ridership) & & & 1 & 0.54 & -0.54 & 0.42 & -0.48 & 0.27 & -0.12 & 0.66 & 0.38 & 0.14 & -0.51 \\
\hline Log (Housing units) & & & & 1 & -0.54 & 0.28 & -0.43 & 0.08 & -0.3 & 0.5 & 0.16 & 0.36 & -0.73 \\
\hline Log (Average Household & & & & & 1 & -0.25 & 0.29 & 0.07 & 0.26 & -0.63 & -0.12 & -0.16 & 0.59 \\
\hline African American population & & & & & & & 1 & -0.35 & 0.43 & -0.51 & -0.28 & 0.14 & 0.45 \\
\hline Asian population & & & & & & & & 1 & 0.004 & 0.13 & 0.4 & -0.1 & -0.23 \\
\hline Unemployment Rate & & & & & & & & & 1 & -0.18 & -0.1 & 0.002 & 0.16 \\
\hline Log (Median Household income) & & & & & & & & & & 1 & 0.28 & 0.06 & -0.54 \\
\hline Log (Number of Jobs) & & & & & & & & & & & 1 & -0.02 & -0.17 \\
\hline Number Bus stations & & & & & & & & & & & & 1 & -0.31 \\
\hline Log (People with No Driving Licenses) & & & & & & & & & & & & & 1 \\
\hline
\end{tabular}

1. Note: $n=126$

2. Variables removed: poverty rate, white population, number of people without vehicle, total population and male percent.

3. Variables that has a VIF higher than 30 were removed based on which variable had the lowest correlation with subway. 


\subsection{Spatial Regression}

At first, the OLS model was developed in GeoDa with the selected independent variables. The queen weight matrix was introduced in the model to connect the spatial units based on first order neighborhood. In such spatial interdependence context, meaning the dependent variable is affected by the weighted average of the dependent's neighboring spatial units, the OLS model becomes inconsistent. Also, such spatial lag is typically correlated with the disturbance or errors (Kelejian et. al, 1997). So, this makes OLS models inconsistent and biased in the presence of spatial autocorrelation. The spatial autocorrelation effect must be accounted for in the model as an endogenous variable to properly explain the variations.

In addition to typical OLS error terms tests, the output of the OLS model in GeoDa included Lagrange Multiplier (LM) and Robust Lagrange Multiplier test results for the suitability of the spatial lag model or spatial error model. Table 7 displays the results of the LM and Robust LM tests.

Table 7: Diagnostics For Spatial Dependence

\begin{tabular}{|l|l|l|}
\hline Test & Value & P-Value \\
\hline Lagrange Multiplier (lag) & 4.5444 & $0.03862^{* *}$ \\
\hline Robust LM (lag) & 3.1251 & $0.07710^{*}$ \\
\hline Lagrange Multiplier (error) & 1.4292 & 0.92050 \\
\hline Robust LM (error) & 0.0100 & 0.10257 \\
\hline
\end{tabular}

Note: * significant at $90 \% \mathrm{CI}$, **significant at $95 \% \mathrm{CI}$

Table 7 indicates that the spatial lag model (SLM) is much more appropriate for the dataset compared to the Spatial Error Model (SEM). Lagrange Multiplier and Robust LM tests for lag showed that the lag LM test values were significant at the $95 \%$ and $90 \%$ level, respectively. On the other hand, Lagrange Multiplier and Robust LM tests for the error were insignificant. This follows the procedure for model seletion of Anselin (2005) after running the OLS model and obtaining the Lagrange Multipliers for both lag and error spatial models. The model with significant Lagrange Multiplier must be considered the most appropriate model and therefore retained. The parameter estimations of the SLM model in the subsequent section will be used to discuss the effects of independent variables on subway ridership. 
Based on the results of LM tests, the current study selected the SLM to determine the effects of the independent variables (i.e., Citi Bike ridership) on the dependent variable (i.e., subway ridership). The SLM adds a spatial lag term in the model formulation. The spatially lagged dependent variable uses the weight matrix, which is the average of the dependent variable in the neighboring areas. Table 8 shows the results of the OLS and SLM. The $\mathrm{R}^{2}$ and $\log$ likelihood values were used as the goodness-of-fit measures in this study. The mehod of estimation for SLM used in GeoDa software is (MLE). 
Table 8: Result Of The Coefficient Estimates Of The SLM And OLS Model

\begin{tabular}{|c|c|c|c|c|c|c|c|c|}
\hline \multirow[t]{2}{*}{ Name of the Variable } & \multicolumn{4}{|c|}{ Ordinary least Squares (OLS) } & \multicolumn{4}{|c|}{ Spatial Lag Model (SLM) } \\
\hline & Coefficient & Std. Error & T-statistic & P-Value & Coefficient & Std. Error & Z-value & P-Value \\
\hline Constant & 9.196 & 1.501 & 6.125 & $0.000 * * *$ & 7.246 & 1.626 & 4.457 & $0.000 * * *$ \\
\hline $\begin{array}{l}\text { Number of Citi Bike } \\
\text { Stations }\end{array}$ & -0.010 & 0.009 & -1.100 & 0.274 & -0.007 & 0.009 & -0.874 & 0.382 \\
\hline Log (Citi Bike Ridership) & 0.105 & 0.038 & 2.762 & $0.007 * * *$ & 0.088 & 0.036 & 2.471 & $0.013 * *$ \\
\hline $\begin{array}{l}\text { African American } \\
\text { population }\end{array}$ & -0.006 & 0.001 & -7.332 & $0.000 * * *$ & -0.005 & 0.001 & -7.260 & $0.000 * * *$ \\
\hline Asian Population & -0.0005 & 0.001 & -0.518 & 0.606 & -0.0004 & 0.001 & -0.452 & 0.651 \\
\hline Log (Number of Jobs) & -0.222 & 0.057 & -3.871 & $0.000 * * *$ & -0.206 & 0.053 & -3.864 & $0.000 * * *$ \\
\hline Number of Bus Stops & 0.024 & 0.003 & 6.987 & $0.000 * * *$ & 0.023 & 0.003 & 7.505 & $0.000 * * *$ \\
\hline $\begin{array}{l}\text { Log (People with No } \\
\text { Driving licenses) }\end{array}$ & -0.457 & 0.193 & -2.364 & $0.020 * *$ & -0.276 & 0.197 & -1.403 & 0.161 \\
\hline Unemployment Rate & 0.013 & 0.002 & 6.665 & $0.000 * * *$ & 0.012 & 0.002 & 6.515 & $0.000 * * *$ \\
\hline $\begin{array}{l}\text { Log (Average Household } \\
\text { Size) }\end{array}$ & -1.114 & 0.149 & -7.479 & $0.000 * * *$ & -1.025 & 0.143 & -7.181 & $0.000 * * *$ \\
\hline End Stations & 0.337 & 0.028 & 12.091 & $0.000 * * *$ & 0.342 & 0.026 & 13.203 & $0.000 * * *$ \\
\hline Transfer Stations & 0.275 & 0.043 & 6.464 & $0.000 * * *$ & 0.278 & 0.039 & 7.053 & $0.000 * * *$ \\
\hline Log (Housing units) & 0.033 & 0.103 & 0.323 & 0.747 & 0.049 & 0.095 & 0.516 & 0.606 \\
\hline $\begin{array}{l}\text { Log (Median Household } \\
\text { Income) }\end{array}$ & -0.431 & 0.098 & -4.406 & $0.000 * * *$ & -0.404 & 0.091 & -4.449 & $0.000 * * *$ \\
\hline$\rho$ & & & & & 0.148 & 0.071 & 2.072 & $0.038 * *$ \\
\hline $\mathrm{R}^{2}$ & 0.866 & & & & 0.871 & & & \\
\hline Log-likelihood & 88.707 & & & & 90.838 & & & \\
\hline
\end{tabular}

Note: Significant variables at $90 \% \mathrm{CI}$ is marked bold with *, at $95 \% \mathrm{CI} * *$, at $99 \% * * * \mathrm{CI}$ 
The coefficient estimates of the SLM shows that Citi Bike ridership, number of African American population, , number of jobs, number of bus stations, unemployment rate, average household size, end stations, transfer stations and median household income were statistically significant. Among the statistically significant variables, Citi Bike ridership, number of bus stations and unemployment rate, end stations, transfer stations were positively associated with subway ridership, while the rest of the significant variables negatively affected subway ridership. The constant between the two SLM and OLS is different. The SLM has a lower constant coefficient than OLS, indicating that SLM explains the variation in the data much better than does OLS. $\mathrm{R}^{2}(0.871)$ for SLM is slightly better than OLS (0.866). the Log-likelihood for SLM (90.838) is better than the loglikelihood for OLS (88.707). The spatial lag $\rho$ coefficient $(0.148)$ is positive which indicant a positive assoction between the neighboring values of the dependant variables. the spatial lag Coefficient had a p-value of 0.038 which is significant at the $95 \%$ confidace level. both models were tested for the Diagnostics for heteroskedasticity in the errors. The p-value for pagan test results for OLS and SLM was 0.27820 and 0.27033 respectively. that proves that there is no correlation in the errors of the two models

The study found the number of Citi Bike stations insignificant and it negatively impacted subway ridership. Adding one Citi Bike station in a subway station's service area resulted in a decrease in average daily subway ridership. This negative effect is likely because of a high number of Citi Bike stations within an area provide easy access to bike sharing services, leading more bike trips to replace subway trips, consequently decreasing subway ridership. Redundancy (i.e. closely spaced) bike sharing station locations was a key concern of the planners of the bike sharing system (Daddio, 2012). In addition to reducing subway ridership, higher bike sharing station density within a subway station's service area minimizes the optimum usage of bike sharing stations/resources. However, Citi Bike ridership around a subway station increased subway ridership. This is because bike trips ending in a subway service area directly served first-mile connectivity to subway trips, whereas bike trips originating in subway service areas served lastmile connectivity. Ma et al. (2015) found a similar positive association between subway ridership and bike sharing trips in Washington, D.C. In light of this finding, transportation agencies should consider installing bike sharings close to transit stations as a way to increase stations' ridership, especially in the case of subway systems. 
The number of the African American population in the subway station's service area negatively affected subway ridership. The number of jobs in the subway stations service area also had a negative impact on subway ridership. The number of bus stops around a subway station positively impacted subway ridership, indicating that bus services complemented the subway service, unlike the number of Citi Bike stations. The number of people with no driving licenses also negatively impacted subway ridership. End stations, transfer stations were associated positively with the subway ridership in the spatial context. Number of housing units had a positive correlation with the subway ridership. The median household income negatively correlated with subway ridership. 


\section{CHAPTER 6: CONCLUSIONS}

This study investigated the impacts of bike sharing services along with other explanatory factors on subway ridership in NYC. Moran's I test of the dependent and independent variables indicated spatial auto-correlation, so modeling purpose spatial regression techniques such as Spatial Lag Model and Spatial Error Model were considered. The Lagrange Multiplier (LM) and Robust Lagrange Multiplier (LM) test results showed that the spatial lag model fits better for the subway ridership data. On the other hand, the OLS model was applied to compare the performance of SLM. In terms of model fitness, both models resulted in similar performance. Although the SLM model provided a slightly better goodness of fit, the difference was insignificant between the two. There were 13 independent variables in the final model to explain the relationship with subway ridership. Number of Citi Bike trips within 0.25-mile radius of a subway station had a positive impact on subway ridership, while the number of Citi Bike stations within the subway station's proximity had a negative impact. Preliminary analysis of Citi Bike ridership also showed that the bike sharing program is becoming more popular in the urban core of NYC. These findings shed light on how to expand bike sharing programs and related infrastructure that could also increase subway ridership. For example, to increase Citi Bike trips around the subway station area (which increased subway ridership), NYC could invest more in bike-friendly transportation systems (e.g. increasing the length of protected/dedicated bike lanes, implementing safety measures such as law enforcement, and installing NYC DOT bike parking facilities near subway stations). However, increasing the number of Citi Bike stations in the subway station service areas reduces the subway ridership - this requires further investigation. 


\section{CHAPTER 7: RECOMMENDATIONS AND FUTURE RESEARCH DIRECTIONS}

Recommended actions for increasing subway ridership in NYC include adding Citi Bike stations with a careful consideration of a 0.25 mile radius from the subway station, which is in accordance with other studies (Ma et. al, 2015; Fan et. al, 2019; Campbell and Brakewood, 2017) and this study findings. Though the Citi Bike ridership was associated with an increase in subway ridership, the station's location had a negative effect on subway ridership. Decreasing the number of Citi Bike stations within a 0.25 mile radius around each subway station could result in an increase in subway ridership. Also, providing dedicated bike lanes to ensure the safety of Citi Bike users could lead to an increase in subway ridership as the bike system continues to complement the subway system and the two become more interwoven.

Some of the limitations for this study include the number of explanatory variables. Considering additional explanatory variables that could potentially improve model performance may be effective in increasing subway ridership and related policy initiatives. This study used the starting stations for the Citi Bike originating trips, but did not consider end stations of bike trips. The current study also did not estimate the elasticity to determine the associated marginal effect of explanatory variables on subway ridership. Applying different modeling techniques could provide additional insights on the potential ways of increasing subway ridership and bike ridership. For future research studies, the impact of the number of Citi Bike stations in a subway station's service area will be worth investigating. Another research direction could be to further investigate why the number of people with no driving licenses negatively affected subway ridership, which was unexpected. 


\section{References}

Anselin, L. (2005). Exploring Spatial Data with GeoDaTM: A Workbook [eBook]. Retrieved from http://www.csiss.org/clearinghouse/GeoDa/geodaworkbook.pdf.

Anselin, L. (2018). Applications of Spatial Weights. Geodacenter.github.io. Retrieved from https://geodacenter.github.io/workbook/4d_weights_applications/lab4d.html.

Anselin, L. (2020a). Applications of Spatial Weights. Geodacenter.github.io. Retrieved from https://geodacenter.github.io/workbook/4d_weights_applications/lab4d.html.

Anselin, L. (2020b). Contiguity-Based Spatial Weights. Geodacenter.github.io. Retrieved from https://geodacenter.github.io/workbook/4a_contig_weights/lab4a.html\#fn1

Anselin, L. (2003). Spatial Econometrics [eBook]. Retrieved from http://web.pdx.edu/ crk1/WISE/SEAUG/papers/anselin01_CTE14.pdf.

Archives of Statistical Summaries. New York DMV. (2020). Retrieved from https://dmv.ny.gov/about-dmv/archives-statistical-summaries.

Bureau, U. (2020). Interactive Maps. The United States Census Bureau. Retrieved from https://www.census.gov/programs-surveys/geography/data/interactive-maps.html.

Burnham, K.P., Anderson, D.R. (2004). Multimodel inference: understanding AIC and BIC in model selection. Sociological methods \& research, 33(2), 261-304.

Campbell, K.B., Brakewood, C. (2017). Sharing riders: How bike sharing impacts bus ridership in New York City. Transportation Research Part A: Policy and Practice, 1(100), 264-82.

Citi Bike NYC. (2020). Citi Bike System Data. Retrieved from https://www.citibikenyc.com/system-data.

Daddio, D. (2012). Maximizing Bicycle Sharing: An Empirical Analysis Of Capital Bikeshare Usage [Ebook]. Retrieved 1 December 2020, From Https://Core.Ac.Uk/Download/Pdf/210605345.Pdf.

Open Data, N. (2020a). Data.cityofnewyork.us. Retrieved 1 December 2020, from https://data.cityofnewyork.us/Transportation/Subway-Stations/arq3-7z49.

Open Data, N. (2020b). Data.cityofnewyork.us. Retrieved 1 December 2020, from https://data.cityofnewyork.us/Transportation/Bus-Stop-Shelters/qafz-7myz. 
Dong N., Huang H., Lee J., Gao M., Abdel-Aty M. (2016). Macroscopic hotspots identification: a Bayesian spatio-temporal interaction approach. Accident Analysis \& Prevention, 1(92), 256-64.

Fan, A., Chen, X., \& Wan, T. (2019). How Have Travelers Changed Mode Choices for First/Last Mile Trips after the Introduction of Bicycle-Sharing Systems: An Empirical Study in Beijing, China [Ebook] (p. 16). Hindawi. Retrieved 1 December 2020, from http://downloads.hindawi.com/journals/jat/2019/5426080.pdf.

Fang C, Liu H, Li G, Sun D, Miao Z. (2015). Estimating the impact of urbanization on air quality in China using spatial regression models. Sustainability, 7(11), 15570-92.

Center for Spatial Data Science. (2020). GeoDa Space. Retrieved from https://geodacenter.github.io/GeoDaSpace/.

ACS 5 Year Socioeconomic Data Tract, 2. (2020). UC Berkeley GeoData Repository. Geodata.lib.berkeley.edu. Retrieved 1 December 2020, from https://geodata.lib.berkeley.edu/catalog/stanford-sx060pc9679..

Kelejian, H., \& Prucha, I. (1997). A Generalized Spatial Two Stage Least Squares Procedure for Estimating a Spatial Autoregressive Model with Autoregressive Disturbances [eBook]. Retrieved from http://econweb.umd.edu/ kelejian/Research/P071897.PDF.

Lambert, D.M., Brown J.P., Florax R.J. (2010). A two-step estimator for a spatial lag model of counts: Theory, small sample performance and an application. Regional Science and Urban Economics, 40(4), 241-52.

Ma, T., Liu, C., \& Erdoğan, S. (2015). Bicycle sharing and public transit: does Capital Bikeshare affect Metrorail ridership in Washington, DC? Transportation research record, 2534(1), $1-9$.

Maps \& Data. (2020). Retrieved from https://www.povertyusa.org/data.

Martin, E. W., \& Shaheen, S. A. (2014). Evaluating public transit modal shift dynamics in response to bikesharing: a tale of two US cities. Journal of Transport Geography, 41, 315-324.

Mattson J, Godavarthy R. (2017). Bike share in Fargo, North Dakota: Keys to success and factors affecting ridership. Sustainable cities and society, 34, 174-82.

Metropolitan Transit Authority. (2018). Subways. Retrieved from 
http://web.mta.info/nyct/facts/ridership/ridership_sub.htm.

Murack, J. (2020). Regression Analysis Using GIS [eBook]. Retrieved from https://libraries.mit.edu/files/gis/regression_presentation_iap2013.pdf.

New York City. (2020). DOT Citywide Mobility Survey. Retrieved from

https://nycmobilitysurvey.com/nycweb/pages/home?locale=en-US. Accessed May 30,2020

New York City. (2018 and 2019). Mobility Report. Retrieved from https://www1.nyc.gov/html/dot/downloads/pdf/mobility-report-2019-print.pdf.

Index Mundi. (2020). New York Population per square mile, 2010 by County. Indexmundi.com. Retrieved from https://www.indexmundi.com/facts/united-states/quick-facts/newyork/population-density\#map.

Noland, R.B., Smart, M.J., Guo, Z. (2016). Bikeshare trip generation in New York City. Transportation Research Part A: Policy and Practice, 94, 164-81.

New York City Department of Transportation. (2020). Citywide Mobility Survey [eBook]. Retrieved from https://www1.nyc.gov/html/dot/downloads/pdf/nycdot-citywidemobility-survey-report-2018.pdf.

Pucher, J., Buehler, R., Seinen, M. (2011). Bicycling renaissance in North America? An update and re-appraisal of cycling trends and policies. Transportation research part A: policy and practice, 45(6), 451-75.

Ramos-Santiago, L.E., Brown J.A. (2016). Comparative assessment of the factors associated with station-level streetcar versus light rail transit ridership in the United States. Urban studies, 53(5), 915-35.

Rixey, R.A. (2013). Station-level forecasting of bikesharing ridership: Station Network Effects in Three US Systems. Transportation research record, 2387(1), 46-55.

Ryan S., Frank L.F. (2009). Pedestrian environments and transit ridership. Journal of Public Transportation, 12(1), 3.

Shaheen, S., Martin, E., \& Cohen, A. (2013). Public Bikesharing and Modal Shift Behavior: A Comparative Study of Early Bikesharing Systems in North America.

Article.nadiapub.com. Retrieved 1 December 2020, from http://article.nadiapub.com/IJT/vol1_no1/3.pdf. 
Siddiqui, C., Abdel-Aty, M., Choi, K. (2012). Macroscopic spatial analysis of pedestrian and bicycle crashes. Accident Analysis \& Prevention, Mar 1;45, 382-91.

Song, J., Du, S., Feng, X., Guo, L. (2014). The relationships between landscape compositions and land surface temperature: Quantifying their resolution sensitivity with spatial regression models. Landscape and Urban Planning, 123, 145-57.

Tobler, W. (1970). A Computer Movie Simulating Urban Growth In The Detroit Region [Ebook] (pp. 234-240). Retrieved 1 December 2020, from https://dces.wisc.edu/wpcontent/uploads/sites/128/2013/08/W5_Tobler1970.pdf.

Arcgis. (2020). USA Population Density. Retrieved from https://hub.arcgis.com/datasets/fab7849b55d54f0f8f246605f6ee9306/data?geometry=$\underline{74.935 \% 2 \mathrm{C} 40.533 \% 2 \mathrm{C}-73.079 \% 2 \mathrm{C} 40.897 \& \text { layer }=9}$.

Washington, S., Karlaftis, M., \& Mannering, F. (2011). Statistical and Econometric Methods for Transportation Data Analysis. Ru.ac.bd. Retrieved 1 December 2020, from http://www.ru.ac.bd/wpcontent/uploads/sites/25/2019/03/202_07_Washington_Statistical-and-EconometricMethods-for-Transportation-Data-Analysis-Second-Edition.pdf.

Zhang, G., Yang, H., Li, S., Wen, Y., Li, Y., Liu, F. (2019). What is the best catchment area of bike share station? A study based on Divvy system in Chicago, USA. IEEE 5th International Conference on Transportation Information and Safety (ICTIS), 1226-1232. 